\title{
Identidades étnicas y territorios indígenas en la obra de don Luis de la Cruz: entre pehuenches, huilliches, llanistas, ranquelinos y pampas (1806)
}

\author{
Florencia Roulet \\ Université de Lausanne \\ florencia.roulet@unil.ch
}

Recepción: 27 de abril de 2010 / Revisión: 19 de noviembre de 2010

Aceptación: 19 de noviembre de 2010 / Publicación: diciembre de 2011

\section{RESUMEN}

Este artículo analiza la percepción que tuvo don Luis de la Cruz acerca de la territorialidad y las identidades indígenas -individuales y colectivas- en su viaje por la cordillera, el norte de la Patagonia y las pampas en 1806, basándose en sus propias observaciones y en los testimonios de sus informantes pehuenches. Los testimonios de sus acompañantes revelan contactos incesantes y flexibles así como un espacio por el que las gentes circulan cruzando fronteras étnicas, adoptando nuevas identidades y creando vínculos que trascienden las enemistades grupales. Las fuerzas centrípetas del comercio y el parentesco son contrarrestadas por la dinámica centrífuga de la guerra, dando lugar al surgimiento de nuevas entidades étnicas en un proceso al que no son ajenas las manipulaciones coloniales.

Palabras clave: Identidades étnicas, territorialidad, pertenencias étnicas, etnogénesis, etnización, etnificación, parentesco, comercio, guerra, Patagonia, Argentina, siglo XIX.

Ethnic identities and indigenous territories in the writings of Luis de la Cruz (1806). Among pehuenches, huilliches, llanistas, ranquelinos and pampas

\begin{abstract}
This article deals with Luis de la Cruz' perception of indigenous territories and identities -individual as well as collective- during his journey through the mountain ranges, Northern Patagonia and the Pampas in 1806, based upon his own perceptions and the testimonies of his pehuenche informants. The personal itineraries of his indigenous mates reveal incessant and flexible interethnic contacts in a vast region where people circulated across ethnic boundaries, adopting new identities and creating bonds that overcame group enmities. The centripetal forces of trade and kinship were counterbalanced by the centrifugal dynamics of war, leading to the emergence of new ethnic identities in a process strongly influenced by colonial manipulations.
\end{abstract}

Keywords: Ethnic identities, territoriality, ethnic belongings, ethnogenesis, ethnization, ethnification, kinship, trade, war, Patagonia, Argentina, $19^{\text {th }}$ Century.

SUMARIO: 1. El desafío: descolonizar nomenclaturas y restituir la historicidad del devenir étnico. 2 . La escolta pehuenche de Luis de la Cruz. 3. Vecinos en discordia: pehuenches, ranquilches, huilliches y llanistas. 4. Migraciones, comercio, visitas y parentesco: fuerzas centrípetas que cohesionan a las sociedades indígenas desde los Llanos de Chile hasta la costa Atlántica. 5. La identidad indígena, un entramado de pertenencias múltiples. 6. Distribución territorial, especialización económica, guerra y alianzas políticas: fuerzas centrífugas que reproducen la diferencia. 7. A modo de conclusión. 8. Referencias bibliográficas. 


\section{EL DESAFÍO: DESCOLONIZAR NOMENCLATURAS Y RESTITUIR LA HISTORICIDAD DEL DEVENIR ÉTNICO}

En los estudios etnohistóricos consagrados a los pueblos indígenas de la región pampeana y norpatagónica, pocos temas se han revelado más complejos que el de dilucidar quiénes se escondían tras la proliferación de nombres impuestos por los testigos españoles y criollos a sus diversos interlocutores nativos. Basándose en la mal comprendida lengua de sus informantes, en la traducción aproximativa de sus intérpretes y en sus propios criterios de clasificación, los colonizadores registraron los rótulos nativos trastocando fonemas, haciendo encajar sonidos inéditos en el limitado abecedario de la lengua castellana e imaginando grafías variables para plasmar en el papel nombres concebidos sólo con el fin de ser enunciados en la conversación. Algunos de esos nombres informaban acerca de la ubicación relativa de los individuos agrupados bajo ese emblema -las gentes del sur, del norte o del este- o resaltaban alguna característica de sus territorios - los habitantes de los pinales, de los montes, de las salinas o de los carrizales, los que viven junto al río o la laguna, en la montaña o la llanura-o bien identificaban a sus principales jefes. Casi todas esas designaciones habían sido atribuidas por individuos ajenos al grupo, y por lo tanto "adscribían identidades más bien que las describían", operación clasificatoria que a menudo se hacía de modo caprichoso e impreciso, asignando diversos nombres a un mismo grupo o un mismo nombre a grupos diferentes ${ }^{1}$.

Prontos en nominar pueblos para ellos desconocidos estuvieron los primeros cronistas, los fundadores de ciudades, los encomenderos ávidos de brazos y los funcionarios acantonados en sus despachos, seguidos por los capitanes de guardias atentos al ir y venir de los indios en torno a los fuertes, los enérgicos jefes de frontera, los diligentes jesuitas ansiosos de aprender y comprender para mejor adoctrinar, los viajeros temerarios, los geógrafos que surcaban el espacio consultando la brújula y el compás y los expeditivos hombres de armas. Cuando tras todos ellos se asomaron los etnógrafos a ese galimatías de etnónimos buscando hallar el "verdadero gentilicio" y la "auténtica designación" de los habitantes indígenas de la región, estos grupos llevaban tres siglos y medio de contacto con el blanco y habían sido recientemente vencidos, desalojados de sus tierras, desmembradas sus familias, acalladas sus lenguas y disuelto para siempre su modo de vida. Entonces, las viejas y sucesivas etiquetas fueron sustituidas por flamantes apelativos que nunca antes habían dejado un rastro sobre los folios amarillentos de los archivos. Por fin aquietados, "reducidos" y congelados en el tiempo, los sobrevivientes fueron observados e interrogados, en la primera mitad del siglo XX, por estudiosos que veían en ellos a los últimos exponentes vivos de pueblos destinados a desaparecer junto con sus idiomas, creencias y costumbres. De esos pocos testimonios -tardíos, de escasa profundidad temporal, y a menudo contradictorios- cotejados con un corto número de fuentes publicadas surgirían los nuevos gentilicios que se les atribuirían con carácter retrospectivo, consumando de tal modo su sometimiento. "Así -nos dice Lidia Nacuzzi- los 'blancos'

\footnotetext{
${ }^{1}$ Weber, 2005, pp. 15-16. En ésta y otras citas del inglés, la traducción es mía.
} 
de casi dos siglos más tarde cumplieron, mediante esa suerte de bautismo colectivo, aquellos objetivos de la Corona española que habían quedado pendientes"2.

En forma paralela, algunos historiadores veían al indígena como el contrincante que había sido necesario derrotar para instaurar la civilización. Sin manifestar curiosidad etnográfica alguna, reprodujeron -en el mejor de los casos- las apelaciones que brindaban los documentos, aunque más generalmente se contentaron con designaciones tan imprecisas como peyorativas: "los indios", "la indiada", "las tribus", "los bárbaros", "los salvajes" o "los infieles". Mediante este procedimiento de identificación exógena reductora y estigmatizante, la diversidad étnica y política quedaba anulada por términos que, a la vez que englobaban en un mismo conjunto al "otro", le asignaban rasgos negativos imputables a su condición aborigen.

Las investigaciones históricas y antropológicas de las últimas décadas han cuestionado radicalmente estos enfoques pero, más atentas a reconstruir el modo de vida, las múltiples adaptaciones de los nativos a las condiciones creadas por la presencia europea, los circuitos de intercambio y los variados fenómenos derivados de la convivencia fronteriza (cautiverio, parlamentos, intentos de evangelización, etc.) no abordaron por lo general el problema de las identidades étnicas, limitándose o bien a reproducir las designaciones que aparecen en sus fuentes, sometiéndolas sólo en contados casos a crítica, o bien a retomar los términos acuñados por los etnógrafos (mapuches, araucanos, tehuelches septentrionales, gününa këna, aónik'enk) asumiendo que remiten a entidades discretas y esencializadas, reconocibles por su lengua, su cultura y modo de subsistencia y pasibles de ser rastreadas hacia atrás en el tiempo hasta el momento inicial de la conquista.

Inspirada en el objetivo de "descolonizar la nomenclatura aplicada a los grupos nativos"3, Lidia Nacuzzi ha procurado deconstruir las categorías utilizadas para asignar identidades étnicas a los grupos de la región pampeana y norpatagónica. Esta investigadora propone dejar de lado las adscripciones vulgarizadas por la etnografía del siglo XX, evitar el considerar las pertenencias étnicas como esencias inmutables, restituyéndoles su carácter histórico, su variabilidad y su apertura al cambio, y volver a las fuentes de archivo, cuyo caudal de información dista mucho aún de haber sido cabalmente explotado ${ }^{4}$. Yendo en el mismo sentido, Guillaume Boccara insiste en la necesidad de "devolver todo su espesor sociohistórico a las sociedades indígenas", viéndolas como producto de un proceso diacrónico en el que no sólo se advierten estrategias de resistencia y continuidades con respecto al período precolombino sino también adaptaciones originales, dinamismo cultural y emergencia de nuevos grupos e identidades. Boccara propone entender el concepto de "etnogénesis", tomado de la

\footnotetext{
${ }^{2}$ NAcuzzi, 2002, pp. 259-289. Para un detallado estado de la cuestión acerca de la atribución de identidades étnicas por la etnografía de la primera mitad del siglo XX, remito a su tesis doctoral: NACUZZI, 1998.

${ }^{3}$ Ibidem, p. 261.

${ }^{4}$ En trabajos recientes, Martha Bechis también ha indagado el tema de las identidades y etiquetas étnicas atribuidas a los grupos indígenas de la frontera sur bonaerense en el siglo XVIII, proponiendo una reinterpretación de términos como el de "auca", que de adjetivo indicando la condición de rebelde y guerrero pasó a convertirse en confuso etnónimo. Véase BECHIs, 2003 y 2004.
} 
literatura antropológica norteamericana, no sólo como el proceso de surgimiento de nuevas entidades étnicas inducido por la invasión europea (por fisión de un grupo originario, fusión de un segmento con un segundo grupo y asimilación de individuos sueltos), sino también como las transformaciones políticas y las formas de definición identitaria de un mismo grupo a través del tiempo, que comprenderían las "adaptaciones y resistencias creadoras de transformaciones que trascienden a menudo las conciencias individuales" ". En paralelo a estos procesos internos se detectan fenómenos de "etnificación" (creación de una entidad étnica por la administración colonial, que la erige en contraparte en las negociaciones políticas) y de "etnización" (lectura de la realidad social y política a partir de un prisma racial y étnico-cultural), por los cuales, desde el exterior, la sociedad "blanca" asigna identidades, rasgos culturales y de carácter, circunscribe territorios e interpreta los conflictos entre indígenas en términos étnicos ${ }^{6}$.

Recogiendo el guante que lanzan Nacuzzi y Boccara, quisiera abordar en este trabajo el tema de las identidades étnicas y la territorialidad de los grupos nativos de la extensa región que se extiende entre la localidad cordillerana de Antuco y el fuerte de Melincué, tal como aparece en los textos elaborados por el comisionado chileno don Luis de la Cruz, que la recorriera en 1806. Su detallado testimonio nos permite obtener un pantallazo de los distintos grupos que poblaban el ámbito cordillerano, norpatagónico y pampeano en las postrimerías del período colonial, vistos desde la perspectiva de uno de sus componentes, los pehuenches de la región de Antuco, que lo acompañaron y constituyeron su principal fuente de información.

Don Luis de la Cruz era alcalde del cabildo de la ciudad chilena de Concepción, órgano que junto con el tribunal del consulado de la misma ciudad comandó una serie de exploraciones de los pasos andinos hacia las pampas entre 1804 y $1806^{7}$. El objetivo de esos reconocimientos era determinar cuál era el camino más directo y llano entre el puerto de Buenos Aires y el de Talcahuano, camino que a su vez facilitaría

[...] la ocupación de los inmensos países situados al este de las cordilleras entre los 34 y 36 grados, que hoy están despoblados o poseídos por algunas hordas de bárbaros que se pueden someter o arrojar hacia el Cabo de Hornos si no convienen con la nueva comunicación ${ }^{8}$.

\footnotetext{
${ }^{5}$ Boccara, 2002, pp. 47, 48, 56-57, 71.

${ }^{6}$ Ibídem, p. 69.

${ }^{7}$ Se trata de los viajes de José Barros, que salió de la villa de Linares y recorrió los pasos de Ancoa y Alicó entre febrero y marzo de 1804; del de Justo Molina, que viajó de Chillán a Buenos Aires por el paso de Alicó entre abril de 1804 y enero de 1805, volviendo a Concepción por el paso de Antuco en mayo de ese año, y del del propio Luis de la Cruz desde el fuerte de Ballenar a Melincué entre fines de marzo y mediados de julio de 1806.

${ }^{8}$ Carta del Cabildo de Concepción al de Buenos Aires. Concepción, 3-II-1804. Archivo General de la Nación (en adelante AGN), IX, 19-7-4.
} 
Estas primeras incursiones debían hacerse de modo pacífico, "con algún pretexto que no manifieste el objeto de su comisión a los naturales del país, para no alarmarlos o causarles sospechas".

Como miembro del Cabildo de Concepción, Luis de la Cruz había analizado y debatido con sus colegas los informes de los comisionados José Barros y Justo Molina, así como las muy escuetas informaciones transmitidas por don Santiago de Cerro y Zamudio, aventurero chileno que había hecho un primer viaje a Buenos Aires y regresado con un mandato de aquel consulado para abrir un camino carretero entre aquella ciudad y la de Talca y para explorar la supuesta junta entre los ríos Diamante y Negro ${ }^{10}$. Mientras que el Consulado de Buenos Aires parecía inclinarse por la ruta propuesta por este último a través del paso del Planchón, frente a Malargüe, el de Concepción prefería el camino explorado por Justo Molina que pasaba por Antuco y resolvió por lo tanto repetir la exploración de la ruta seguida por Justo Molina, quien iría como práctico o baqueano, pero encargando esta vez la empresa a "un sujeto instruido y de luces como lo es el Alcalde Provincial don Luis de la Cruz", acompañado de "una persona práctica en el uso de la brújula y el sextante que supiera determinar rumbos y calcular latitudes"11.

Así es como este militar y activo vecino de Concepción se lanzó a una aventura que lo convertiría en etnógrafo malgré lui. Luis de la Cruz no había cumplido aún los cuarenta años y decía haber pasado la mayor parte de su vida "en colegio sin nociones de los campos"12. Pero desde inicios de la década de 1790 había recorrido la frontera sur de su país hasta adquirir un cabal conocimiento de la región. Si bien no hablaba el mapudugun, como sí era el caso de los tres exploradores que lo habían precedido ${ }^{13}$, debía estar bastante familiarizado con esa lengua, a juzgar por la gran cantidad de expresiones que salpican su discurso, y contaba con los servicios de intérpretes como el propio Justo Molina, el capitán de amigos Leandro Jara y el soldado Pedro Baeza, buenos conocedores del universo pehuenche.

A diferencia de los diarios de Cerro y Zamudio, Barros y Molina ${ }^{14}$, los escritos de Luis de la Cruz constituyen un testimonio etnográfico de valor excepcional. Des-

\footnotetext{
${ }^{9}$ Ibídem.

${ }^{10}$ Instrucciones del Consulado de Buenos Aires a José Santiago de Cerro y Zamudio. Buenos Aires, 30-VI-1803. AGN, IX, 19-7-4.

${ }^{11}$ Oficio del comandante Luis de Alava al Consulado de Buenos Aires. Concepción, 5-XI-1805. AGN, IX, 39-5-5.

${ }^{12}$ De La Cruz, 1969b, p. 401. Luis de la Cruz nació en Concepción en 1768. Ingresó a las milicias como teniente de caballería en 1791, siendo promovido a ayudante mayor en 1798 y a capitán en 1800, año en que viajó a Buenos Aires cumpliendo una misión confidencial. Tras su viaje a las pampas en 1806 fue ascendido a coronel. Murió en Santiago en 1828. CARRETERO, 1969.

${ }^{13}$ Los miembros del cabildo de Concepción presentan a José Barros y a Justo Molina como hombres "que han tenido frecuente comunicación y amistad con los Pehuenches" (Carta del cabildo de Concepción al de Buenos Aires. Concepción, 3-2-1804. AGN, IX, 19-7-4), mientras que Cerro y Zamudio se ufana de "la intimidad y confianza con que me comunican como Lenguaraz". Carta de Cerro y Zamudio al virrey. Buenos Aires, 6-VI-1803. AGN, IX, 30-7-4.

${ }^{14}$ El primer viaje de Cerro y Zamudio fue editado por Pedro de Angelis y el de Barros por Jorge Fernández (FERnÁndeZ, 1982), mientras que el de Molina, inédito, puede consultarse en AGN IX, 19$7-4$.
} 
de el inicio de su misión, el comisionado se había propuesto "expresar en cada día las juntas de indios que se ofrezcan, las parlas y visitas que me hagan" y noche tras noche, robándole horas al sueño, se quedó a la lumbre tenue de una vela volcando por escrito los acontecimientos de la jornada para que su memoria, que sabía frágil y selectiva, no lo traicionara ${ }^{15}$. El paisaje que descubría, los hechos de que era testigo, las arengas que pronunciaba, los objetos que distribuía, las declaraciones que recogía eran transformados en texto aún en caliente, sin dar tiempo a que el olvido realizara su implacable obra de reelaboración del recuerdo. Tan atento a medir distancias, a evaluar recursos y a señalar dificultades de la ruta como a registrar sus diálogos con cada indio, india o cautiva, Luis de la Cruz transmite el eco de esa multitud de voces indígenas. Eco traducido, claro está, resumido y cargado de las valoraciones del escribiente, que nos revela sin embargo hasta qué punto era esencial para la propia supervivencia del viajero su comunicación con los nativos.

La frontera sur de Chile y el Rio de la Plata a fines del periodo colonial

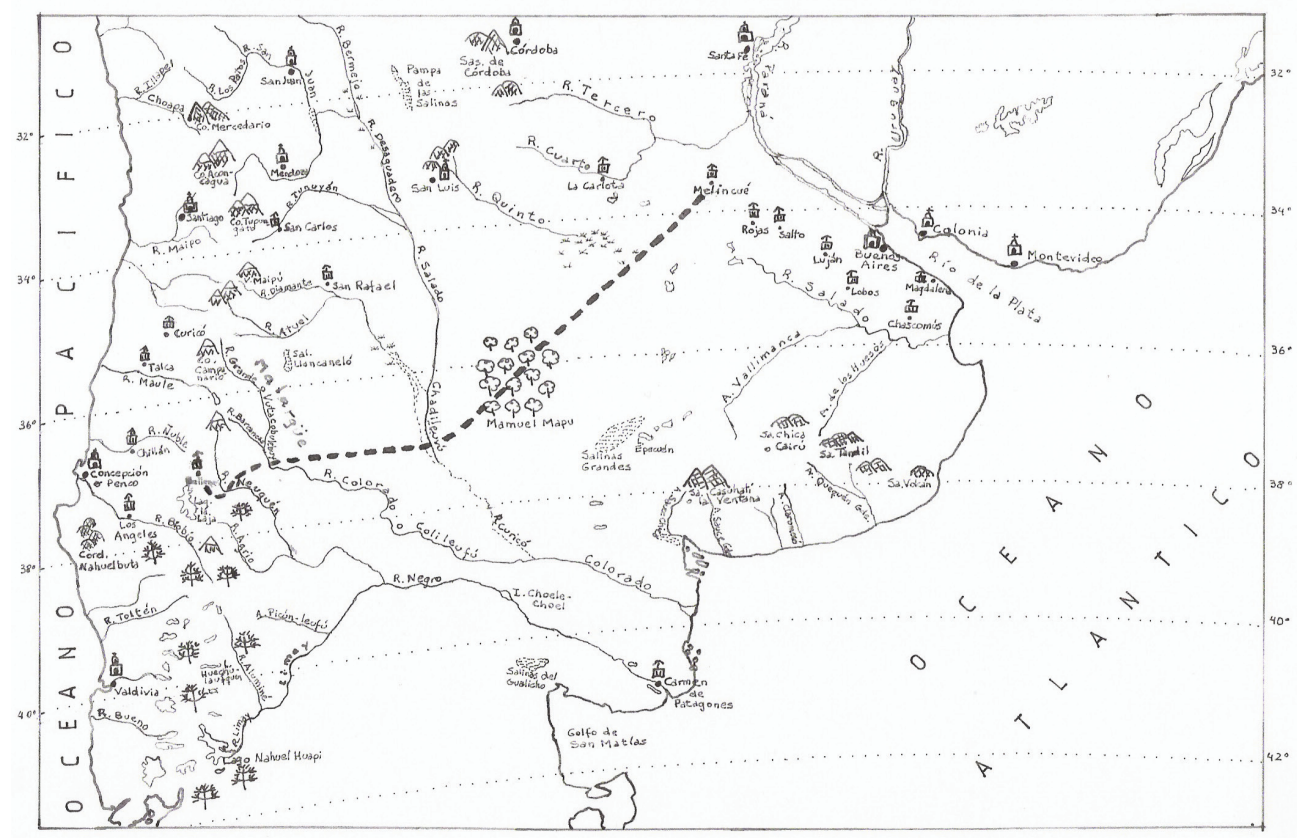

$\stackrel{1}{\longrightarrow} \stackrel{1}{\longrightarrow}$

Esa permanente voluntad de diálogo requiere que el otro sea visto como un genuino interlocutor: los indios que describe Luis de la Cruz no son las sombras silenciosas y serviles que apenas adivinamos en tantos relatos de expediciones y cautiverios tierra adentro sino personas dotadas de voz propia, actores esenciales de un periplo

${ }^{15}$ De La CRUz, 1969a, pp. 45-46. 
que saben imposible sin su concurso y eximios oradores que manejan la palabra con la misma pericia que la lanza ${ }^{16}$.

Al término de su expedición, Luis de la Cruz redactó tres extensos documentos: el diario, seguido por una Descripción de la naturaleza de los terrenos que se comprenden en los Andes poseídos por los peguenches y por un Tratado importante para el perfecto conocimiento de los indios peguenches, según el orden de su vida. $\mathrm{Si}$ estas ricas fuentes ya han sido abundantemente aprovechadas como cantera de datos geográficos, etnográficos e históricos, la originalidad de este ejercicio basado casi exclusivamente en un único corpus documenta $1{ }^{17}$ pretende ser la de reflexionar sobre la identidad étnica y "el devenir de los sujetos colectivos" a partir de los relatos autobiográficos de los caciques que acompañaron al viajero, cuyas "pertenencias... aparecen proyectadas o denegadas retrospectivamente sobre el sujeto autobiográfico, en distintas etapas de su vida"18. En efecto, las historias de vida que narra el alcalde chileno revelan una realidad social en la cual los contactos son incesantes y flexibles, reorientándose según las circunstancias. Sus peripecias describen un vasto ámbito por el que las gentes se mueven cruzando fronteras étnicas, adoptando nuevas identidades, cultivando vínculos que trascienden las enemistades grupales, movilizando antiguas pertenencias para recuperar espacios sociales, mezclándose constantemente y dando lugar al surgimiento de nuevas entidades étnicas, en un proceso al que no eran ajenas las manipulaciones debidas a la política colonial.

\section{LA ESCOLTA PEHUENCHE DE LUIS DE LA CRUZ}

En el otoño austral del año 1806, don Luis de la Cruz emprendió el largo viaje que partiendo del fuerte cordillerano de Ballenar, cerca del paso de Antuco, debía llevarlo a Buenos Aires, a orillas del río de la Plata. Su delicada misión consistía en explorar los territorios intermedios para, una vez obtenido el consentimiento de sus habitantes, proponer el trazado de un camino carretero por donde circularan libremente viajeros y comerciantes haciendo un trayecto más corto y directo que el que unía entonces Santiago con Mendoza y la capital del virreinato.

La suya era una expedición pacífica de reducidas dimensiones: apenas veinte hombres, entre soldados, peones, oficiales, agrimensor y el práctico Justo Molina

${ }^{16}$ Todo discurso indígena transcrito por una persona ajena a su cultura es un discurso cautivo: "una lógica 'occidental' substituye al indígena en la exposición narrativa o argumentativa de los hechos; los conceptos originales se vacían de su contenido para poder pasar por 'occidentales'; los núcleos más irreductibles, más resistentes a su transformación, se suprimen". Sin embargo, a condición de "limpiar la ganga escritural que medio lo oculta" para liberar la voz indígena, estos testimonios "pueden leerse como un género discursivo privilegiado que expresa a un tiempo las estrategias y tácticas respectivas de los dos antagonistas en presencia". LienHARD, 1998, pp. 10, 26.

${ }^{17}$ En trabajos anteriores (Roulet, 1999-2001; 2002; 2006; 2008; 2009) he abordado el tema de la frontera sur a partir de documentación de numerosos archivos en Argentina y España. Mi objetivo en este artículo es concentrarme en la información etnográfica que figura en los voluminosos escritos del comisionado Luis de la Cruz.

${ }^{18}$ EsCOLAR, 2000, p. 261. 
-quien había reconocido parte del proyectado camino el año anterior-, armados con sólo once pistolas para su defensa, ya que contaban granjearse la buena voluntad de los indios gracias a los obsequios que abultaban sus cargas y a las promesas de amistad, comercio y comunicación que hacían en nombre de las autoridades de Chile. Para llevar a buen término tan largo viaje, además de armas y regalos, los chilenos precisaban baqueanos que los guiaran en tierras desconocidas, intermediarios que los introdujeran ante los grupos que encontrarían en el trayecto y guerreros que los protegieran durante la marcha. Sólo hombres de confianza podían cumplir esas funciones. Lógicamente, acudieron a sus viejos aliados pehuenches, guardianes de la cordillera, en cuyos terrenos se había erigido el fuerte de Ballenar en 1788. De ellos dependía el cruce de los Andes y la suerte de la expedición.

El primer paso de Luis de la Cruz fue convocarlos a una junta en la que, una vez leídas y explicadas las instrucciones del viaje, se formó la comitiva que habría de acompañarlo hasta Buenos Aires. Tras algunas vacilaciones y desistimientos, la integraron cinco caciques principales, de los más renombrados entre los pehuenches de Antuco, que no sólo tenían considerable peso en la jerarquía política aborigen, sino que poseían a la vez un conocimiento práctico del terreno en las pampas orientales: se trataba de los ancianos Payllacura, Puelmanc y Manquel, y de los jóvenes Manquelipe y Mariñán.

De los tres mayores, Payllacura era hermano del venerable cacique Calbuqueu, a quien se reservaba el privilegio de ser el primer orador en las parlas; Puelmanc era famoso por haber logrado en su juventud la hazaña de quitar la vida al rebelde cacique Llanquitur -enemigo jurado de españoles y de pehuenches- ${ }^{19}$ y Manquel, el último en sumarse a la comitiva, era nada menos que el cacique gobernador de los pehuenches. Payllacura y Puelmanc, así como el joven Mariñan, habían vivido varios años entre los ranqueles de Mamilmapu, el "país de los montes", donde seguían teniendo cantidad de parientes y conocidos. Gracias a su prolongada experiencia en esas tierras, Puelmanc obtuvo el privilegio de guiar a los chilenos hasta las tolderías de Carripilum, el principal cacique ranquel. En cuanto a Manquelipe, "cacique mozo y bien acreditado" que parecía de unos veinticinco años pero resultó tener más de cincuenta, se lo tenía por valiente y fiel a los españoles ${ }^{20}$.

${ }^{19}$ Otras fuentes confirman este hecho: al enterarse de la muerte de Llanquetur, el comandante de armas de Mendoza consultó sobre "el premio que dará al Indio Pulmain que logró este triunfo". Carta de Sobremonte a Loreto. Córdoba, 5-II-1789. AGN, IX, 30-4-8. En efecto, Amigorena había prometido a los pehuenches un premio de 500 yeguas por la muerte de Llanquetur y proponía repartirlas "entre todos los caciques capitanejos y demás que se hallaron en la acción [...] bien que a Puelmain se le puede mejorar, para que los demás entren en codicia viendo la ventaja con que a éste se le prefiere". Carta de Amigorena a Sobremonte. Mendoza, 13-I-1789, en AHM 55/18.

${ }^{20}$ De La Cruz, 1969a, pp. 62, 410. Los cinco caciques se desplazaban, a su vez, con sus propios acompañantes: Payllacura con un mozo, Puelmanc con dos de sus hijos y dos mocetones, Manquelipe con su hijo, Mariñan con cuatro mocetones y Manquel con su esposa doña Carco -única mujer viajera mencionada en el relato- y dos mocetones, de modo que la expedición estaba integrada por un número parejo de indios y de chilenos. 
En el transcurso de los tres meses que duró el viaje, Luis de la Cruz tendría ocasión de conversar largo con todos ellos y llegaría a conocer cantidad de detalles acerca de sus vidas personales que constituyen una vía privilegiada para acceder, desde una perspectiva autobiográfica, al complejo tema de las identidades étnicas.

\section{VECINOS EN DISCORDIA: PEHUENCHES, RANQUILCHES, HUILLICHES Y LLANISTAS}

¿Quiénes son, en efecto, los indios que aparecen a lo largo del trayecto? De los pehuenches escribe De la Cruz que vivían en el sector oriental de la cordillera entre los 34 y los 37 grados de latitud sur, en tres partes separadas: al norte, en Malargüe, los Malalquinos; más al sur los de Balbarco, establecidos al este de la localidad chilena de Chillán, a la que solían bajar, y el tercero y meridional, de donde provenían sus escoltas, los de Antuco ${ }^{21}$. No mucho tiempo atrás los pehuenches estaban presentes también al oeste de los Andes, pero el asentamiento gradual de población hispanocriolla en la región los había corrido al norte del río Neuquén, penetrando en la región de Malargüe, y también hacia el este donde, más allá de los abrigados valles cordilleranos con sus bosques de pehuén y sus ricas pasturas estivales, se abre la infinita planicie pampeana ${ }^{22}$.

Lo primero que percibió De la Cruz es que las relaciones entre el conjunto de los pehuenches y sus vecinos eran esencialmente hostiles:

[...] conserva esta tribu la desunión con las otras; y de unos en otros días se asaltan, maloquean o roban, sin que las reprima ni contengan las paces que celebran en los parlamentos generales de Chile a que todos asisten ${ }^{23}$.

Este era el caso con los ranqueles de Mamilmapu, sus vecinos nororientales. Pese a que ambos pueblos habían concluido paces en la frontera mendocina en $1799^{24}$, la tensión que los oponía seguía siendo palpable. El gobernador Manquel tenía aún fresca la memoria de una ocasión, muchos años atrás, en que más de doscientos pehuenches que cazaban guanacos en Auquinco habían sido exterminados por los

${ }^{21}$ De La Cruz, 1969c, p. 447.

${ }^{22}$ De sus recorridas por las campiñas chilenas desde 1790 dice de la Cruz que "los planes del poniente de los Andes, cuyos valles los ocupaban los indios peguenches y se ignoraba su fecundidad, hoy se ven poblados de nosotros, de nuestros bienes y de nuestra agricultura [...] como lo tengo dicho en la introducción a Antuco, toldería que fue de nuestros amigos montañeses". DE LA CRUZ, 1969b, pp. 401, 402. Los subrayados son míos. El desplazamiento de los pehuenches parece haber sido producto de una orden de expulsión adoptada de fines de la década de 1760 que exasperó a muchos caciques, descontento que no se arregló cuando el gobernador dispuso el destierro a Lima de algunos líderes pehuenches y cuando una parcialidad entera de esos indios, refugiada en Chillán, fue degollada por los cristianos. Villalobos, 1989, pp. 128-132. A partir de la década de 1790 el intendente de Concepción inició una política de colonización en el área cordillerana conocida como la Isla de la Laja, que terminó de desplazar a los pehuenches hacia el este de los Andes.

${ }^{23}$ De La Cruz, 1969c, p. 437.

${ }^{24}$ Roulet, 2002, pp. 92-93. 
ranqueles "sin que hubiese quedado uno que lo contase, sino los cuerpos en el campo como bestias, y los rastros de estos nacionales, para conocer que ellos habían sido los del destrozo..." ${ }^{25}$. Al final del viaje, los recelos de Manquel lo llevaron incluso a pedir la protección directa del comisionado y sus soldados, "pues estos indios ranquelinos tendrán por aquí amistades y se embriagarán todos los días. Han sido nuestros enemigos, y la bebida refresca los agravios: pudiéramos tener algún pleito, y así te pido dos soldados para que estando enfermos [borrachos] me déis, afin de que los sujeten" 26 .

Consciente de los resentimientos latentes entre ambos pueblos, Luis de la Cruz formularía al entrevistarse con el gobernador ranquel Carripilum un pedido especial para favorecer a su amigo Manquel:

[...] este cacique y todos los demás peguenches que me acompañan debo recomendártelos, pues son, como yo, extranjeros, y los contemplo tristes, porque los he sentido muy callados entre la multitud de tus gentes. Cualquiera merced o cariño que les hagáis, lo hacéis a mi persona, y te lo agradeceré más. Si yo solicito nuestra unión y amistad, es de consiguiente la de ellos, pues son nuestros amigos ${ }^{27}$.

Carripilum respondió que cumpliría las reglas de la hospitalidad, pero en cuanto dio la espalda a Manquel y sus hombres confió al chileno su verdadera opinión: "estos peguenches son unos lobos indomables [...] porque no tienen fidelidad con nadie" 28 .

Enemigos, extranjeros, lobos: pehuenches y ranqueles no se aprecian ni confían unos en otros. La memoria de los pasados agravios sigue pesando en la construcción que cada quien hace de la imagen del otro, signada por la desconfianza y la traición. En un claro proceso de marcación, unos y otros se endilgan cualidades negativas a las que ni unos ni otros quieren ser asociados ${ }^{29}$.

Pero los ranqueles, en ese momento histórico, no son el peor rival de los pehuenches. El adversario más temido son los huilliches, "gentes del sur", nombre que aplican a tres conjuntos de indios que, pese a ser designados con idéntico término, no constituyen un mismo conglomerado étnico ni político. El grupo con el cual las relaciones son más belicosas es el capitaneado por Guerahueque, contiguo al territorio pehuenche; al sur de éstos está el grupo dirigido por Cagnicolo, con el que las relaciones son más armoniosas, y por último el de los "patagónicos o magallánicos", quienes aliados con Cagnicolo hacen la guerra a pie contra los huilliches de Guerahueque ${ }^{30}$. Este primer grupo parece formar con los indios de los Llanos al oeste de los Andes una única entidad política, bajo la autoridad superior de Guerahueque. El territorio de los huilliches de Cagnicolo (o al menos su influencia política), que

\footnotetext{
${ }^{25}$ De La Cruz, 1969a, pp. 243-244.

${ }^{26}$ Ibidem, p. 357.

${ }^{27}$ Ibidem, p. 272. Los subrayados son míos.

28 Ibidem.

${ }_{29}$ Tomo el concepto de «marcación» de Escolar, 2000, p. 266, quien lo define como el acto de "recrear la diferencia en 'otros' a quienes se transfiere el estereotipo estigmatizador, lo cual supone tácitamente que el grupo original se despoja del estigma”.

${ }^{30}$ De La Cruz, 1969c, pp. 447-448. De los huilliches de Cagnicolo y sus aliados magallánicos dice De la Cruz que son "un mismo cuerpo para defenderse". De LA CRUz, 1969c, p. 448.
} 
principia al sur del río Limay, también se extiende al oeste hasta el Pacífico ${ }^{31}$. El primer conjunto de huilliches aparece en el relato de Luis de la Cruz como una presencia amenazadora, siempre al acecho: "hubieron tiempos en que los guilliches de Guerahueque estuvieron en guerra con estos peguenches, y así todo el año estaban con las armas en las manos, y tenían unidas sus tolderías" ${ }^{2}$. Es claro que para los pehuenches, aquellos tiempos no estaban del todo superados, ya que aún temían los ataques de sus vecinos y habían solicitado auxilio de soldados españoles armados que defendieran sus tolderías en su ausencia, "pues pudieran los Guilliches venir a maloquearlos". Tampoco dejaron de hacer circular rumores sobre las intenciones hostiles de sus contrincantes, quienes "no querían que pasasen españoles para Buenos Aires" y estaban listos a salirles al paso "a atajar, o acabar con mi expedición"33. La memoria pehuenche está saturada del recuerdo de recíprocos asaltos, con muerte de valerosos guerreros y captura de mujeres, niños y ganados. "Los llanistas y guilliches -previene el cacique Calbuqueu en otra clara maniobra de marcación- no son de confiar, y los ciega la codicia y el rencor que conservan con los españoles ${ }^{34}$.

Hasta la anciana hermana de Manquel, cuya edad la convierte en bruja con el poder de vaticinar el futuro, se siente obligada a contarle en el momento de la partida el nefasto sueño que la ha desvelado:

${ }^{31}$ Sobre la unión entre huilliches y llanistas bajo el liderazgo de Guerahueque, observa De la Cruz que ambos "en la actualidad estaban mal con nosotros" por temor a que se repoblara Villa Rica y pregunta si no es Guerahueque quien "manda a los guilliches y sujeta a los llanistas". De LA CRUz, 1969a, p. 111. Sobre la influencia política de Cagnicolo al oeste de los Andes, Manquel informa que éste vivía a tres días de viaje de Osorno y "daría noticia de todos los terrenos de su situación, hasta la costa de Chiloé, Osorno y Valdivia". Ibídem, p. 131. De la Cruz juzga de primera importancia una alianza con Cagnicolo "para conseguir el descubrimiento de las tierras Patagonas, y caminos para Chiloé, Osorno y Valdivia, por estos montes". Ibídem, p. 175.

${ }^{32}$ De La Cruz, 1969c, p. 453. Sus informantes no relatan la génesis de ese perdurable encono, pero sabemos que se remonta por lo menos a fines de la década de 1780, cuando los pehuenches del Reñileuvú liderados por el cacique Currilipi y sus parientes de Malargüe y Antuco lograron ultimar a Llanquetur (diciembre de 1788), seguido del ataque de Currilipi contra las tolderías del huilliche Millaguayqui en el que fueron muertos "muchos indios y dos o tres caciques e hijos de caciques". Comandancia de armas de Mendoza al gobernador de Córdoba. Mendoza, 8-V-1790. Archivo Histórico de Mendoza (en adelante AHM), 55/24 y Carta de Esquivel Aldao a Amigorena. Fuerte de San Carlos, 27-III-1790. AHM, 66/10. Al año siguiente, Currilipi asaltó a traición al huilliche Lepnopan, "principal caudillo de las Pampas y segunda persona del famoso Llanquetur", quien le había solicitado paces y mediación para tratarlas con los españoles. Carta de Amigorena al gobernador. Mendoza, 5-X-1791. AHM, 55/28, y carta de Esquivel Aldao a Amigorena. Fuerte de San Carlos, 4-X-1791. AHM, 66/55. El cacique gobernador pehuenche Currilipi se había granjeado tal odio de parte de los huilliches, que a principios de 1792 fue asesinado brutalmente con toda su familia por una coalición de "Guilliches, Ranquelches, Muluches de los llanos y Pichyhuelchés" capitaneados por los caciques Buenhumilla (viejo compañero de Llanquetur) y el huilliche Guerahueque, el mismo que seguía atemorizando a sus vecinos pehuenches en 1806. Carta de Esquivel Aldao a Amigorena. Fuerte de San Carlos, 8-III-1792. AHM, 66/61 y Comandancia de armas de Mendoza a los ministros de real hacienda. Mendoza, 16-II1792. AHM, 55/19.

${ }^{33}$ De La CRUZ, 1969a, pp. 63, 94, 82.

${ }^{34}$ Ibídem, p. 110. A lo largo de todo el diario, Pedro de Angelis transcribe "llanistas" (habitantes de los Llanos de Chile) como "llamistas". En las citas textuales he corregido ese error. 
Pobre caballero - le dice abrazándolo-, que anoche soñé que saciabas la sed de los guilliches; mucho siento te vayas. [Acto seguido]...todos los indios tomaron la conversación sobre el sueño, que tiene sobre ellos tanto dominio, que en sucediéndoles fatal, dejan cualquier empresa ${ }^{35}$.

Aguerridos, amenazadores, sedientos de sangre, cegados por la codicia y rencorosos con los cristianos, los huilliches de Guerahueque -o más bien, lo que los pehuenches dicen de ellos- van conformando el malvado de la historia sin que podamos ver reflejada su propia voz en el relato. Se nos aparecen como un pueblo aparte, cuyo territorio está claramente delimitado del de sus vecinos septentrionales. Los pehuenches aseguran "que por el costado del sur su línea divisoria con los guilliches es el estero de Curaguenague [o Cariguenague]-leubu", que "nace de la cordillera nombrada Deguin", poco antes de llegar al Limay ${ }^{36}$. También es clara la demarcación espacial con los ranqueles. Al cruzar el Chadileuvú, De la Cruz es consciente de entrar en tierras ajenas:

Amigos, -dice a sus acompañantes- este río que acabamos de pasar, es el deslinde de tus tierras con los indios de Mamilmapu: hasta aquí habéis venido con la seguridad que nos franquean vuestras propiedades, pero adelante no podemos andar sin pedir venia a los caciques y gobernadores ${ }^{37}$.

Así pues, informado por los pehuenches de Antuco, Luis de la Cruz percibe en el transcurso de su viaje al este de los Andes varios conjuntos humanos que se distribuyen en territorios bien delimitados y que parecen tener identidades distintas y contrastantes. Por un lado, los pehuenches en la vertiente oriental de la cordillera ${ }^{38}$; más al sur, los diferentes "otros" que estos designan como huilliches, extendiéndose hacia el Pacífico unos y hacia el Atlántico los demás, los de Guerahueque estrechamente asociados en sus empresas militares y económicas con los indios de los Llanos de Chile y los de Cagnicolo con los indios de las costas patagónicas, unos y otros enfren-

${ }^{35}$ Ibídem, p. 133. Sobre la atribución de poderes sobrenaturales a las mujeres mayores, cf. RouLET, 2008

${ }^{36}$ De La Cruz, 1969a, p. 168.

${ }^{37}$ Ibídem, p. 214.

${ }^{38}$ Reproducimos aquí a grandes rasgos las designaciones que brinda el viajero. Podemos asumir que sus acompañantes pehuenches nombraban a sus vecinos con términos que no forzosamente fueran los que estos usaban para autodesignarse. Notamos que los pehuenches de Malargüe nunca son llamados "pehuenches" sino "los de Malalque" o "malalquinos" salvo en el Tratado importante (DE LA Cruz 1969c, p. 458), donde el autor cita el testimonio de un soldado chileno. Otros etnónimos mencionados son "patagones", "nomentuchus" del sur que "habitan en la costa" (ibídem, p. 87), "puelches" (ibídem, p. 135), "puelches del sur" (ibídem, p. 297), "araucanos", citando al abad Molina (ibídem, p. 450) y "magallánicos" (De la Cruz, 1969a, p. 128 y De la Cruz, 1969c, p. 448). Nótese la ausencia total de términos como "aucas", "mapuches" o "tehuelches". 
tados entre sí $^{39}$. Por fin, en las pampas de Mamilmapu, los ranqueles ${ }^{40}$. A excepción de los patagónicos, que eran pedestres, grandes corredores y más corpulentos, que no criaban ganados españoles, hacían toldos de piel de guanaco, cazaban con boleadoras y flechas, se vestían con pieles y probablemente hablaran otra lengua ${ }^{41}$, las diferencias entre los tres grandes conjuntos no abarcaban el plano de la cultura, ya que todos los demás se expresaban en mapudugun, vivían en toldos de piel de caballo, usaban parecida vestimenta y afirmaban "que las costumbres de aquellos [ranqueles] son las mismas que las de éstos [pehuenches] y sus ritos iguales"42. Vemos así que:

[...] la fuente de la identidad no es la diferencia cultural, sino la comunicación cultural, que permite trazar fronteras entre los grupos a través de símbolos comprensibles tanto por los insiders como por los outsiders ${ }^{43}$.

${ }^{39}$ Algunos de estos "huilliches" vivían en bosques de araucarias y es probable que se consideraran a sí mismos "pehuenches". Es de presumir que se autoidentificaran refiriéndose al paraje en que habían nacido ellos o sus padres (Ruca Choroy, Cunquitra, etc.). Del mismo modo, aquellos que los pehuenches llaman lelfunches (pertenecientes al Lelfün-vutanmapu, región de los Llanos de Chile) o moluches (deformación de nguluches, "gentes del oeste") y que el comisionado designa como llanistas, prefieren identificarse a partir de su lugar de origen (Boroa, Maquegua, Lonquimay...).

40 De la Cruz usa el etnónimo "ranquelinos" o bien "gente de Mamilmapu", traduciendo probablemente el término "mamuelche" ("gentes del monte"), consignado en varios documentos contemporáneos. Nótese que Mamilmapu es un sector muy arbolado de la llanura, que se distingue del resto de la pampa. En su Tratado importante, identifica tres grupos asentados en la planicie: los de Mamilmapu, los "pampas" o "pampistas", "que son los que viven al oriente de estos montes", y los guilliches, "que son los que habitan al [sur] de las Salinas, hacia la costa" y mantienen relaciones hostiles con los pampas. De La CRUZ, 1969c, p. 447.

${ }^{41}$ De la Cruz no llega a ver personalmente a estos "patagones" o "magallánicos". Su información proviene de Payllatur, quien conoció a su gobernador Napayanté, muerto por los pampistas. Estos patagones de Napayanté también tenían guerra con los nomentuchus, "que son los que los consumen", y con los huilliches y llanistas de Guerahueque, a quienes maloqueaban en alianza con Cagnicolo: "en sus malones son bravísimos, y no se dan hasta morir o vencer; y que Canigcolo tiene tanto ejército, por los muchos patagones que saca a la retaguardia, que vienen a pie con flechas". De LA CRUz, 1969a, pp. 87-88. Los malones de Cagnicolo y su infantería de patagones contra estos huilliches eran tan frecuentes que el propio Guerahueque se había lamentado ante Manquel de que "vivía en continua inquietud", a lo que el pehuenche "se ofreció a tratar de paz, o ir de mediador a lo de dicho Cagnicolo para que se verificase" (ibídem, p. 132). Patagones de la costa atlántica asociados a huilliches cordilleranos para asaltar a sus vecinos norteños huilliches y llanistas: he aquí una imagen de la conflictiva dinámica intertribal muy distinta de la que nos brinda la clásica teoría de la "araucanización de las pampas", donde los "belicosos araucanos chilenos" habrían masacrado y sustituido a los "pacíficos tehuelches patagónicos".

${ }^{42}$ De La Cruz, 1969a, pp. 103, 106. Algunos huilliches de Cagnicolo se vestían como los patagónicos, otros como los huilliches de Guerahueque y los pehuenches, "según la nación con que más versan" (DE LA CruZ, 1969c, p. 447).

${ }^{43}$ Poutignat - Streiff-Fenart, 1995, p. 135. La traducción es mía. 


\section{MIGRACIONES, COMERCIO, VISITAS Y PARENTESCO: FUERZAS CENTRÍPETAS QUE COHESIONAN A LAS SOCIEDADES INDÍGENAS DESDE LOS LLANOS DE CHILE HASTA LA COSTA ATLÁNTICA}

Esta uniformidad cultural se debe a varios factores. Por un lado, al constante trasvase de individuos y de grupos enteros de un conjunto a otro, ya sea como botín humano en sus frecuentes conflictos, ya como emigrados voluntarios que optan por refugiarse entre sus agresores o sus vecinos más bien que perpetuar una guerra en la que se saben de antemano perdedores. Según explicó Manquel, luego de la matanza de pehuenches en Auquinco por los ranqueles

[...] se fueron despoblando sus terrenos de hombres y de mujeres, llevándoselas cautivas; y varias familias que vivían por Ranquel, otras por Treuco, y otras por Cobuleubu, tomaron el partido de venir a implorar el asilo de estos mismos enemigos, por no morir en manos de ellos en aquellos montes ${ }^{44}$.

También había indios de las pampas que se refugiaban en la cordillera. Poco antes de cruzar el Chadileuvú, la expedición se cruzó con gentes de Mamilmapu que hacía más de un año venían caminando desde Curamalal, cerca de las Salinas Grandes, con el objetivo de irse a vivir entre los huilliches, por temor a "los continuos asaltos y malones que los pampistas les daban". La constante inquietud los había forzado a abandonar sus tierras, "saliendo como fugitivos en busca del sosiego y seguridad". Al encontrarse con los pehuenches cambiaron de idea y prefirieron encaminarse a lo de su pariente, el cacique pehuenche Carrilon ${ }^{45}$.

Otro factor que promueve la homogeneización cultural es el comercio, que no cesa incluso en tiempos de conflicto y que engloba igualmente a la sociedad colonial, proveedora de bienes que se han hecho esenciales para las economías nativas (yeguas, alcohol, utensilios de hierro, cereales). Luis de la Cruz deja constancia de que en medio de la agitación que les causa la posibilidad de un ataque huilliche, hay pehuenches que van a las tolderías de aquellos a comerciar. Uno de ellos, "que había andado entre los guilliches en conchavo", supo que el principal Guerahueque había salido "con comercio para los llanos, y oyó decir que Millalen salía luego para Mendoza con el propio objeto", lo que lo obligaba a cruzar territorio pehuenche ${ }^{46}$. Enseguida se supo también de Caullan, que "acaba de llegar de lo de los guilliches" contando que Guerahueque "había vuelto de su conchavo con los muluches o lelbunchees" ${ }^{47}$. Al entrar en Mamilmapu, los expedicionarios se encontraron con huilliches que "vienen a conchavo a estas tierras de Mamilmapu, y su destino es la reducción de Carripilum". De la Cruz observó la importancia en la economía indígena de estos trueques de ganado, con frecuencia robado por los ranqueles en las estancias españolas, a cambio de ropa, alcohol y objetos de metal cambalacheados en la frontera, así como de textiles

\footnotetext{
${ }^{44}$ De La Cruz, 1969a, p. 244.

${ }^{45}$ Ibídem, p. 197.

${ }^{46}$ Ibídem, p. 94

${ }^{47}$ Ibídem, p. 110.
} 
indígenas: "todos los años pasaban reducciones enteras [de huilliches y llanistas] para Mamilmapu, por permutar los ponchos por haciendas" y viceversa, los indios de las pampas se mudaban periódicamente a las cordilleras con sus ganados ${ }^{48}$.

Los intercambios que vinculan a los distintos pueblos de la región revelan una complementariedad de actividades entre ellos y con la economía colonial que combina el trueque, las razias y la cría de ganado, volviéndolos interdependientes. "Los llanistas, los guilliches, los peguenches y demás naciones tienen con estos indios de Mamilmapu un comercio muy vasto de animales, y para mantenerlo, roban hasta donde pueden ${ }^{49}$.

En su Tratado importante anota que "todos los indios compran los tintes [vegetales] a los peguenches y guilliches, y principalmente los de Mamilmapu y pampas" 50 . De los ranqueles dice que "su comercio no es otro que permutar: [...] son afectos a herrajes de plata, chupas, espuelas, uples, botones y otras baratijas que adquieren con animales" ${ }^{51}$. A los pehuenches recomienda "tratar amistosamente [con] aquellas tribus [de Mamilmapu]... porque sus mantas, lanas y obras de las que aquí hacen sus mujeres, allí valen tres, ó cuatro veces más" 52 .

$\mathrm{Ni}$ apegados a tradiciones fosilizadas, ni autosuficientes y reacios al contacto, los indígenas de la larga frontera sur habían constituido un vasto espacio económico que, pese a los periódicos estallidos bélicos, articulaba los territorios no sometidos del Pacífico al Atlántico con las áreas controladas por el Estado colonial, en un flujo ininterrumpido de bienes y personas ${ }^{53}$.

Un tercer factor de cohesión en esas sociedades constituidas por segmentos autónomos en perpetua competencia son las visitas protocolares que realizan sus jefes entre sí y el asiduo envío de noticias a través de indios correos: ese mismo verano el gobernador pehuenche Manquel había escoltado al baqueano Justo Molina hasta lo de Guerahueque, su acérrimo enemigo, para prevenirlo sobre la proyectada expedición de Luis de la Cruz. Cuatro años atrás, Manquel y su esposa Carco habían visitado al huilliche Cagnicolo, que vivía más allá del río Limay. Lo encontraron "de rostro agradable, afable, y de muy buena presencia", haciendo honor a las reglas de la hospitalidad. Manquel se había emparentado con él y conversado largamente sobre el estado y la conservación respectiva de sus pueblos. Desde entonces, "siempre pensaba

${ }^{48}$ De LA CRUZ, 1969a, pp. 196, 230. Al penetrar en territorio ranquel, la expedición encontró indios de Mamilmapu que, según los caciques pehuenches, "vendrían de Guiñantu, esto es para trasladarse a las cordilleras" (ibídem, p. 224). En su Tratado importante, De la Cruz explica que cuando escasea el pasto en los campos donde pacen sus ganados, los indios se mudan a otro sitio, "cuya mutación llaman quinantu: esta costumbre hace que el que más hacienda tiene, menos dure en un lugar". DE LA Cruz, 1969c, p. 449. Esteban Erize da el verbo huinamn como "acarrear, trasladar" (ERIze, 1989, p. 60) y Rosas explica huyñamn, huyñamtun como "acarrear, y lo toman por mudarse de habitación" (RosAs, 1995, p. 209). La movilidad geográfica es consustancial a las economías pastoriles.

${ }^{49}$ De La Cruz, 1969a, p. 231.

${ }^{50}$ Ibídem, p. 331.

${ }^{51}$ De La Cruz, 1969c, p. 430.

52 De La Cruz, 1969a, pp. 201, 81.

${ }^{53}$ Véanse Palermo, 1991 y Casanova, 1996. 
enviar sus palabras a lo de Canigcolo"54. A poco de iniciar su viaje, De la Cruz supo que "el mismo Manquelipe -uno de sus escoltas- mandaba correos a los guilliches, avisando de las providencias que se daban, y del tiempo en que debía caminar mi comitiva". Estos emisarios o werkenes también venían desde las tolderías huilliches. La llegada de uno de ellos a los toldos de Manquel provocó un verdadero revuelo por su vestimenta fuera de lo común: "Es imponderable la suspensión de ánimo que Manquel padeció al oír de que venía con pieles vestido. Medio se entrelevantó, y me dijo: -Curreo guilliches, lengua, lengua". El atuendo de este "indio empellejado" no impidió que De la Cruz le reconociera jerarquía de embajador ${ }^{55}$.

Personas, familias y parcialidades enteras que emigran al territorio de otras naciones, relaciones comerciales, visitas protocolares e intercambios de información son otros tantos puentes tendidos entre grupos étnicos a menudo enfrentados en conflictos sangrientos. Pero el factor que más incidencia tiene para la cohesión de estos pueblos rivales es el parentesco estrecho que los vincula desde generaciones atrás, revelador de una compleja trama de escisiones, fusiones y mestizajes que caracteriza tanto el proceso de constitución de nuevos conglomerados étnicos y de nuevas formas de definición identitaria de un mismo grupo a través del tiempo -etnogénesis- como la fluidez de las identificaciones individuales en toda la región pampeana y norpatagónica.

Asombrado por la multitud de parientes con la que se encontraban sus acompañantes en Mamilmapu, Luis de la Cruz preguntó a Manquel cómo se había poblado ese territorio. El anciano cacique le contó lo que había oído de sus propios antepasados: "Que en estos terrenos habitan indios desde tiempos inmemoriales" y que Quiñeipil, que había sido un belicoso gobernador pehuenche, mantenía guerra constante contra huilliches, llanistas e indios de Mamilmapu hasta que estas tres naciones se coaligaron para asaltarlo a un tiempo desde diferentes partes. Poco a poco fueron destruyendo sus tolderías y obligando a sus indios a abandonar los territorios cordilleranos de Ranquel o Ranquil -al sur del río Neuquén, cerca de las cabeceras del Agrio- para refugiarse en las pampas. Que entonces, cuarenta años atrás, se había venido una de sus propias hermanas "y otros peguenches que aquí han procreado, y han llenado estas tierras. Que la mayor parte de habitadores, que en el día hay, son descendientes de aquellos montes" $" 56$.

Los hechos que Manquel relata a De la Cruz se pueden rastrear en documentos producidos en Chile a fines de 1764, cuando los pehuenches Curipil y Peillipil (seguramente, el mismo Quiñeipil del que hablaba Manquel) pidieron apoyo militar de los españoles para combatir a sus enemigos que formaban una "compañía de más de mil y quinientos hombres armados y congregados, de los que llaman guiliches, de los indios de Maquegua, de Rucachoroy, de Guachipen y Tumenco y Ranquel Mapu ${ }^{57}$.

\footnotetext{
${ }^{54}$ De La CruZ, 1969a, pp. 129, 124.

${ }^{55}$ Ibídem, pp. 91, 84, 115, 116. Las cursivas están en el original. El hecho de que Manquel exclamara "lengua, lengua" seguramente indica que el embajador empellejado, sin duda "patagónico", no hablaba mapudugun y que hacía falta un intérprete para comunicarse con él.

${ }^{56}$ Ibidem, pp. 243-244.

${ }^{57}$ Los franciscanos de la misión de Santa Bárbara transmitieron el pedido de auxilio que les habían hecho llegar los líderes pehuenches "de la otra vanda de las dos cordilleras", el gobernador Francisco
} 
Asistidos por un destacamento español, los pehuenches liderados por el cacique Manquel (tío del que acompañaría décadas más tarde a De la Cruz) desbarataron las tolderías huilliches en enero de 1765. Esa campaña hispano-pehuenche, que los chilenos consideraron un éxito, abrió una caja de Pandora. Tras la efímera victoria se inició un ciclo de venganzas de sangre que terminaron a la larga siendo devastadoras para ambos pueblos. Enzarzados durante cuatro décadas en una guerra sin cuartel contra los huilliches y sus aliados en los llanos de Chile y las pampas, los pehuenches no pararían de contar sus muertos y de deplorar a sus parientes cautivos, entre los cuales Trecalan, el propio hijo de aquel "famoso peguenche Manquel, digno de memoria por su mucha fidelidad con los españoles", a quien De la Cruz conoció en las pampas "sumamente pobre [...] como salido de un cautiverio" 58 . Poco a poco, cantidad de familias abandonarían sus territorios cordilleranos en oleadas sucesivas para instalarse en Mamilmapu, mezclándose con sus ocupantes y convirtiéndose con el correr de los años en la nación ranquel ${ }^{59}$.

Así pues, el expedicionario Luis de la Cruz va descubriendo a medida que transcurre su viaje que estas naciones enemigas que se profesan tanto odio y se consideran extranjeras entre sí son, en realidad, miembros de una misma familia mal avenida, primos hermanos malquistados por viejas historias que se pierden en un pasado cada vez más lejano. Hasta el mismísimo Carripilum, cacique principal de los ranqueles que había sido en su juventud capitanejo del renombrado Llanquitur era, como éste, originario de la cordillera. Cuando la gran rebelión que había sacudido a Chile y Cuyo en los años 1769-70, durante la cual los pehuenches se escindieron entre aquellos que permanecieron fieles a los españoles y los que se unieron a los rebeldes, los indios de Llanquitur se aliaron con los huilliches y llanistas sublevados y se mantuvieron desde entonces en guerra contra los pehuenches leales a los cristianos. Tras la muerte de su jefe Llanquitur en diciembre de 1788 y la captura de una de sus hijas en un malón pehuenche, Carripilum prometió que, si le devolvían a su hija, "él y toda su familia abandonaría aquellos montes y buscaría otra parte más distante en que vivir con alguna tranquilidad". El pehuenche Calbuqueu accedió a su súplica por "cierto amor que le conservaba, como que había sido uno de sus hermanos, uno de los suyos, pues no podía negar era peguenche ranquilino". Fiel a su palabra, Carripilum "no

Curipil y su sobrino, don Pedro Pignupil, Pignapil, Pignipil o Peillipil para defenderse de sus enemigos huilliches que los hostigaban desde hacía más de un año. Fray Francisco Sánchez Areste, fray Juan de San Antonio, Procurador de Misiones al Gobernador de Chile. Santa Bárbara, 31-XII-1764. Archivo Nacional de Chile, Fondo Morla Vicuña, vol. 24, f. 24, citado por León Solis, 1998, p. 125. Según el gobernador de Chile, los pehuenches "padecían muchas estorciones de otra nación que se halla en las tierras inmediatas a las pampas de Buenos Ayres ocupando hasta el río Bueno", con el apoyo de los llanistas de Maquegua, lo que había motivado el auxilio militar que se les prestó. Carta de Guill y Gonzaga al rey. Concepción, 1-3-1765. Archivo Nacional de Chile, Fondo Morla Vicuña, vol. 24, f. 36v., citado por León Solís, 1998, pp. 134 y 144. Véase también Villalobos, 1989, pp. 123-127.

${ }^{58}$ De La Cruz, 1969a, pp. 207, 208.

${ }^{59}$ Idéntica sorpresa manifestó un año antes Justo Molina al enterarse "que los indios que habitan en Mamilmapu no son Huilliches, como se supone y aún yo mismo creía; que son Pehuenches, Pampinos, descendientes de la cordillera, por cuyo motivo se nombran Ranquilinos, pues el lugar de donde eran se llamaba Ranquil, cuyo sitio viene a estar a las dereceras de Santa Bárbara”. Diario de Justo Molina. Concepción, 19-VI-1805. AGN, IX, 19-7-4. 
tardó mucho tiempo en trasladarse con los ranquelinos, que vivían en Mamilmapu, que es donde vive ahora". Emigración desgarradora, ya que "nada puede ofrecérseles más doloroso a los indios que abandonar sus tierras, y así pudo el temor impeler a Carripilum a que se mudase a Mamilmapu"60.

Con él se había ido también Quillán, cacique que De la Cruz conoció como "el más alzado y la cabeza principal" de los ranqueles que vivían por el camino de Salinas. En una arenga memorable destinada a convencerlo de lo infundado de su desconfianza hacia los españoles, el pehuenche Puelmanc evocó su pasado común:

¿No te acuerdas que por creer a tus llanistas abandonaste a tu nación peguenche, cuya recomendación da algún aprecio a tu persona? No te dijeron entonces los llanistas, y a mí también, que los españoles estaban alzados; corrieron la noticia, y sólo algunos peguenches no se alzaron: y éstos, por fieles a los españoles, con su auxilio nos acosaron y nos hicieron desamparar nuestras tierras [...] ¿No te acuerdas de aquellas aguas tan buenas, de aquellos pastos, de aquellos mallines? ¿Los vendiste, los diste por tu voluntad, los di yo, los dio Carripilun, etc.? No fue así. Los desamparamos por nuestras pocas fuerzas, por nuestro error, por los llanistas ${ }^{61}$.

Así explica Puelmanc, el baqueano de Luis de la Cruz, por qué incluso él, tras haber alcanzado la gloria de ser el matador de Llanquetur, había abandonado sus tierras y su gente para refugiarse entre esos mismos indios cuyo líder había ultimado hasta que la nostalgia de su tierra natal lo hizo volver. El alzamiento contra los españoles, ese "error" de los ranquelinos, lo había empujado fuera de la órbita pehuenche.

\section{LA IDENTIDAD INDÍGENA, UN ENTRAMADO DE PERTENENCIAS MÚLTIPLES}

La trayectoria de Puelmanc, como la de los demás acompañantes de Luis de la Cruz, ilustra de modo ejemplar la permeabilidad de las fronteras étnicas, la fluidez de las pertenencias y los incesantes cruces y mestizajes que caracterizan al mundo indígena desde los Llanos de Chile hasta las tolderías de Tandil y Casuhatí. Si bien la violencia es omnipresente en las relaciones intergrupales, no observamos una inva-

${ }^{60}$ De La Cruz, 1969c, pp. 461-462. Una vez en Mamilmapu, los emigrados ranqueles tampoco se quedarían quietos. De la Cruz conoció al cacique Payllaquin, nacido en Mamilmapu, quien siendo mocetón se había ido "para los puelches del sur" con su padre -hermano de Carripilum-, quien "tenía conocimiento de aquellas tierras y por esta razón lo llevó". Se había criado y hecho muchas amistades entre estos puelches a proximidad del río Limay. Ya adulto, Payllaquin había regresado a Mamilmapu y vivía bajo la dependencia de su tío Carripilum. De LA CRUZ, 1969a, pp. 297-298. Este hombre de Mamilmapu designa como "puelches del sur" (puelches huilliches) a los grupos que los pehuenches llaman huilliches a secas, diferenciándolos por el nombre de su principal cacique. Lo interesante es notar que, vistos desde Mamilmapu, los territorios de estos "puelches" no están situados al este sino al sudoeste. Sólo serían puelches stricto sensu ("gentes del este") vistos desde los Andes lo que sugiere que Payllaquin los designaba con el nombre que les había dado su padre, oriundo de la cordillera. Vemos así cómo, en el lapso de una generación apenas, un geónimo se convierte en gentilicio.

${ }^{61}$ De La Cruz, 1969a, pp. 243, 282, 302-303. 
sión masiva y unidireccional, con eliminación de los vencidos y su sustitución por un pueblo vencedor - tal como lo insinúa la clásica representación del fenómeno designado como "araucanización" de las pampas ${ }^{62}$ - sino intercambio, adopción, mezcla y adaptación recíproca.

La emigración obliga al cruce de una frontera social, cruce que acarrea la renuncia a una identidad y la asunción de una nueva. En su diáspora hacia las pampas, los pehuenches dejan sepultada en sus bosques de araucarias la propia identificación como "gentes del pehuén" y renacen como ranqueles. De su hermana, emigrada a las pampas cuatro décadas atrás, dice el cacique Manquel "que fue peguencha" ${ }^{63}$. Al presentarse ante Luis de la Cruz, Puelmanc le había anunciado que él y Payllacura lo acompañarían por "haber sido de Mamilmapú": nótese el matiz semántico que introduce ese haber sido en vez de haber vivido en. Así expresaban los emigrados el cambio de pertenencia que los llevó a una identificación total con sus anfitriones. El matador de Llanquitur se convirtió poco después en personaje clave de la jefatura ranquel. Reputado por su bravura, Puelmanc llegó a ser consejero de Carripilum, "y en todos los malones llevaba la voz" ${ }^{64}$. Del mismo modo que la hermana de Manquel, el guerrero pehuenche se había convertido en genuino ranquel, lo que atestigua la identidad de "cacique Puelmanque de la Nación Ranquelche" con la que se había presentado diez años antes en Mendoza para reclamar a sus sobrinitos, cautivados por los pehuenches de Malargüe y entregados a los españoles ${ }^{65}$.

¿Cómo se verifica ese cambio en la identificación individual de quienes traspasan las fronteras étnicas? ¿De qué modo logran ser aceptados por quienes hasta poco antes eran sus acérrimos enemigos? En estas sociedades donde se vive cara a cara entre parientes, el individuo solo no existe. Nadie puede permanecer en territorio ajeno sin integrarse plenamente al cuerpo social, entretejiendo su existencia con las demás en una urdimbre de solidaridades y afectos, ocupando el lugar y las responsabilidades que el colectivo le asignan. El parentesco, real o ficticio, es la vía de "naturalización" por excelencia. Al mudarse a Mamilmapu, Puelmanc debió casarse con una mujer ranquel, insertándose así en una amplia red de familiares hacia los cuales adquiriría obligaciones y derechos. Nada dice Luis de la Cruz sobre esa unión, pero cuenta

${ }^{62}$ Para un enfoque crítico de esa visión maniquea del fenómeno designado como araucanización, véanse los trabajos de Crivelli Montero, 1994, Ortelli, 1996 y Boccara, 1998, p. 302. El primero habla de la marcha gradual de la araucanización procediendo por infiltración y fusión a través de alianzas comerciales y matrimoniales, adaptándose a las condiciones peculiares de la geografía, el clima y los recursos pampeanos sin dejar rastros arqueológicos reconocibles, y afirma que los choques entre nativos de las pampas e indios "araucanos" fueron escaramuzas breves entre coaliciones efímeras y no una guerra étnica. La segunda se pregunta si la "araucanización" no es ante todo una construcción de los etnólogos, proponiendo incluso pensar en la "pampización" de los araucanos. El tercero inscribe ese fenómeno complejo y progresivo en la larga duración, describiéndolo como un profundo movimiento de aculturación interna que desemboca en la formación de una zona de intercambios y de redes de alianza que vinculan el espacio situado entre los dos océanos, imagen que este trabajo tiende a confirmar.

${ }^{63}$ De La Cruz, 1969a, p. 241. El resaltado es mío.

${ }^{64}$ De La Cruz, 1969a, pp. 59, 216.

${ }^{65}$ Informe del comandante José F. de Amigorena sobre el parlamento realizado con caciques Pehuenches y Ranquilches. Mendoza, 16-8-1796. AHM, 55/19. 
que Puelmanc le habló de "un hijo que iba también a ver, y que solicitaría llevarlo al señor virrey para que conociese a todos sus descendientes por finos vasallos del soberano" ${ }^{\prime 6}$. Ese hijo, Leubumanque, se sumó más adelante a su comitiva junto con otros parientes de Puelmanc entre los que aparece un cuñado, Quiñanancu, lo que parece probar que Puelmanc se había casado y procreado en aquellas tierras ${ }^{67}$.

Si para un individuo adulto el matrimonio representa el expediente más sencillo de integración a un nuevo conjunto social, para los niños y los jóvenes se trata de la adopción en una familia del grupo receptor o del vínculo del lakutun que se establece entre tocayos creando entre ellos una fraternidad simbólica ${ }^{68}$. La adopción de personas externas -cautivos y refugiados, tanto indios como blancos y negros- era una estrategia frecuente que contribuía a reforzar el caudal demográfico de pueblos duramente afectados por las guerras, los desplazamientos forzados y las epidemias periódicas que sucedieron a la conquista española. Los recién llegados reemplazaban a los familiares fallecidos, colmaban un vacío en los menguados linajes y permitían su reproducción a largo plazo, sobre todo si eran mujeres ${ }^{69}$.

Los casos de Payllacura y Mariñan ilustran el funcionamiento de este mecanismo de incorporación. Payllacura y su hermano mayor Calbuqueu, descendientes de pehuenches, habían pasado su niñez en tierras de huilliches hasta que éstos se resintieran con Calbuqueu y ambos se volvieran a vivir con los pehuenches. Payllacura quedó entonces a cargo del indio Rancubil, quien por temor a los malones huilliches emigró a las pampas llevándolo consigo. Se instalaron en Cachacama, a un día de distancia de la guardia de Luján. Muerto su protector, Payllacura "se acogió a lo del cacique Cachimilla" o Catremilla, poderoso cacique ranquel de la región de Salinas Grandes. En algún momento, en circunstancias que De la Cruz no consigna, Payllacura había regresado a vivir entre los pehuenches ${ }^{70}$.

En cuanto al joven Mariñan, que había sido presentado a Luis de la Cruz por su tío, el pehuenche Millatur, era en realidad indio llanista nacido en Boroa, "y de muy mediano se fue a las pampas, donde se crió en lo de Quinchepi" o Quintrepi. Después de muchos años, un hermano suyo había ido a buscarlo pero él se negó a partir enseguida: "por retornar con su asistencia los bienes que había adquirido o merecido de aquel cacique, no quiso tener el gusto de venir a ver a sus parientes hasta que él mismo se lo mandase". El vínculo con Quintrepi era tan fuerte que tenía precedencia sobre los lazos de sangre. Sólo cuando su protector lo autorizó a partir, el joven llanista rumbeó hacia territorio huilliche, que debía cruzar para regresar entre los suyos. "Allí

${ }^{66}$ De La Cruz, 1969a, p. 312.

${ }^{67}$ Ibídem, p. 328.

${ }^{68}$ Véase Zavala, 2000, pp. 57-61. Para un ejemplo más tardío de la integración entre los ranqueles por adopción y tocayazgo, véase mi análisis del caso del coronel Baigorria. RouLET, 2003.

${ }^{69}$ Véase el interesante análisis que hace James Axtell de los tres tipos de adaptación indígena a la catástrofe demográfica causada por la irrupción europea en América del Norte, reacciones que se verificaron también en el extremo sur del continente: la guerra contra enemigos indígenas o coloniales para capturar prisioneros que una vez adoptados reemplazaran a sus propios muertos; los matrimonios mixtos; el refugio cultural y militar junto a vecinos más poderosos o parientes lejanos. AxTeLL, 1992, pp. 106-107.

${ }^{70}$ De La Cruz, 1969a, p. 86. 
estaba su suerte": se enamoró de una pehuenche, cautiva de los huilliches. Sin medir riesgos se la robó, llevándola enseguida a los toldos de Millatur, tío de la muchacha, donde con satisfacción de todos la tomó por esposa. Mediante ese matrimonio el llanista borogano Mariñan, que tras su adopción por Quintrepi había sido ranquel, se convirtió en pehuenche, acrecentando a su reputación de hombre leal la de valiente:

Es fiel y agradecido -le dijo Millatur a Luis de la Cruz-, pues no quiso desamparar al que lo crió por venir a lo de sus parientes [...]. Habiendo tenido valor para robar la mujer que hoy posee, será cona [guerrero] y en cualquier peligro podrá defenderte, hasta rendir la vida ${ }^{71}$.

En estas condiciones de integridad personal y falta de oportunismo, la adopción sucesiva de identidades no afectaba la consideración de la que gozaba Mariñan entre ranqueles y pehuenches. Si demostraban el coraje y la fidelidad de su padre, sus hijos podrían aspirar a ocupar la máxima jerarquía en la jefatura pehuenche.

En efecto, el mismo cacique general de los pehuenches era un ejemplo acabado de la asimilación de extraños operada mediante el parentesco. Los antepasados de Manquel por vía paterna eran huilliches:

[...] todos nacieron en los pinales de Cunquitra, de cuyo lugar vino su padre a casarse a estas tierras, que las baña el presente río de Reynguileubu [Reñileuvú]. Que ya casado, se quedó aquí, y nació él peguenche, cuando por el orden natural debía haber sido guilliche, pues las tierras llaman a los varones, y no a las mujeres. Que cada día se alegra más de aquella determinación, de haberse establecido aquí su padre ${ }^{72}$.

Existe pues una regla de filiación según la cual la identidad étnica y el patrimonio se transmiten por vía paterna. Pero existe también el libre albedrío y cuando un hombre decide radicarse entre los parientes de su esposa sus hijos heredarán la identidad de la madre, sin perder sus derechos territoriales entre la parentela paterna, que pueden reclamar si deciden volver al terruño ancestral: "Las propiedades de aquellas tierras - explica Manquel- no las ha enajenado, y serán suyas, y de sus descendientes siempre"73. La misma legítima expectativa tendría Mariñán al emprender el regreso a los Llanos luego de su prolongada estadía en Mamilmapu.

Así pues, de los cinco caciques pehuenches que escoltaron a De la Cruz, cuatro al menos -Payllacura, Puelmanc, Manquel y Mariñán ${ }^{74}$ - encarnaban de modo cabal los mestizajes, desarraigos, migraciones y adaptaciones sucesivas a nuevos entornos que constituían la circunstancia habitual y definían el recorrido individual de la mayor parte de los indígenas de ese espacio y tiempo. Es inútil buscar pehuenches, llanistas, ranqueles o huilliches "puros": todos estos pueblos están movidos por "una lógica social específica cuyo principio sería la incorporación del Otro en la construcción

${ }^{71}$ Ibídem, p. 118.

${ }^{72}$ Ibidem, pp. 89-90.

73 Ibidem, p. 90. En efecto, cada linaje pehuenche detenta derechos exclusivos a un sector del bosque de araucarias, designado como lobpehuen. Clément, 2005.

${ }^{74}$ De la Cruz brinda muy poca información acerca de la vida de Manquelipi, el quinto cacique. 
dinámica del Sí-Mismo", "lógica mestiza" que, a través de sutiles mecanismos de diferenciación y de incorporación, "produce lo indígena"75.

La serie de ejemplos que brinda el relato de Luis de la Cruz revela que la adopción de una nueva identidad no borraba completamente las anteriores: las pasadas pertenencias permanecían encapsuladas, en estado de latencia, hasta que algún acontecimiento particular o la mera anticipación de la muerte avivaban la nostalgia del emigrante y el deseo de volver a la tierra donde reposaban los restos de sus antepasados. El expatriado podía dar marcha atrás y recuperar su identidad latente, profundamente arraigada en la geografía de su infancia. Así había sucedido con Puelmanc y con Payllacura:

Ya eres viejo como yo -dice Puelmanc al desconfiado Quillán-. Yo me retiré a mis antiguos terrenos; estoy gozando de la tranquilidad, y de mis propiedades, que sólo el corazón de los españoles me pudieran proporcionar ${ }^{76}$.

En Mancol, territorio pehuenche, Luis de la Cruz había conocido al indio Callbutripan

[...] que en el día era peguenche de estas reducciones, y poco antes era de los ranquelinos de Mamilmapu; pues aunque aquí nació, fue a crecer y envejecerse en aquellas tierras, que ahora abandonó, por venir a morir en las que fueron de sus padres, y a disfrutar de los tiempos pacíficos que gozan estos peguenches ${ }^{77}$.

En Michinguelú, corazón de Mamilmapu, recibió la visita del ranquel Cayunan, "que ha sido de nuestros peguenches, quien se vino a estas tierras como los otros". Oyéndolos hablar, su hermana, también originaria de Antuco, se acordó con nostalgia "de sus españoles y tierras, y prometió que se iba este año con su hermano para los Andes" ${ }^{78}$. El emigrado que vuelve tiene la certeza de ser bien recibido y de recuperar el lugar físico y social que había sido suyo antes de partir.

\section{DISTRIBUCIÓN TERRITORIAL, ESPECIALIZACIÓN ECONÓMICA, GUERRA Y ALIANZAS POLÍTICAS: FUERZAS CENTRÍFUGAS QUE REPRODUCEN LA DIFERENCIA}

Si las fronteras étnicas tienen tal permeabilidad, si las identificaciones personales son hasta ese punto inestables, ¿qué elementos dan permanencia a la identidad colectiva de cada grupo? ¿Cómo es que a pesar de mestizajes, trasvases de población y asimilación de los extraños al interior del cuerpo social, a pesar del uso generalizado de una misma lengua y de una cultura material compartida no se diluyen las diferencias y siguen en pie las distinciones entre conjuntos étnicos? El territorio, como vimos, es uno de esos elementos: cada grupo sabe exactamente dónde empieza y termina

\footnotetext{
75 Boccara, 2002, p. 72.

76 De La Cruz, 1969a, p. 303.

77 Ibídem, p. 103.

${ }^{78}$ Ibídem, pp. 315, 317.
} 
el suyo y a partir de qué punto se mueve en espacio ajeno ${ }^{79}$. Cierta especialización económica caracteriza también a cordilleranos y pampeanos: mientras que huilliches y pehuenches explotan los piñones, la madera y las plantas tintóreas de sus bosques, extraen sal de las salinas neuquinas, crían ovejas y cambalachean los ponchos y mantas de lana tejidos por sus mujeres, los ranqueles crían ganado propio o lo obtienen en sus malones contra las fronteras, lo engordan y lo revenden a sus vecinos, que suelen venir de muy lejos a abastecerse. Condicionadas por la geografía, las diferencias en el modo de vida son menores pero revelan una relativa especialización y complementariedad económicas dentro de un vasto sistema de intercambios. En este contexto de interdependencia, lo que determina la persistencia de una frontera social entre unos y otros es la guerra.

El conflicto endémico entre segmentos que viven en pugna permanente a pesar de compartir una misma cultura es generador de etnicidad en la medida en que actualiza un límite entre "nosotros" y "ellos". Olvidándose que lo une un parentesco estrecho a los ranqueles, Manquel ve en ellos a extranjeros enemigos, mientras que Carripilum, al llamar "lobos" a los pehuenches, borra de un plumazo su previa identidad de hombre de los piñones. La larga guerra fratricida ha producido un límite y genera una memoria en la que alternan los hechos heroicos con los agravios que claman por venganza ${ }^{80}$ :

La educación que dan a sus hijos sólo se reduce a contarles las hazañas o hechos valerosos de sus padres y parientes, para criarles grande espíritu, y a ponderarles cuánto importa saber hablar con arrogancia, para alegar en favor de la nación en la materia que les ocurra. También les instruyen de sus tierras, y de las de sus antepasados, a fin de que no pierdan sus derechos, y en especial de toda la parentela ${ }^{81}$.

A través de la educación, con su énfasis en la memoria de las gestas bélicas ancestrales y en el inventario exhaustivo de sus posesiones territoriales, los padres transmiten a sus hijos una identidad, ya que

[...] lo que determina la pertenencia de una persona a un grupo determinado es esencialmente la influencia ajena: la influencia de los prójimos -parientes, compatriotas, correligionarios- que intentan apropiárselo, y la influencia de los de enfrente, que procuran excluirlo ${ }^{82}$.

${ }^{79}$ Para un análisis de la identidad pehuenche desde la perspectiva de la territorialidad, véase Clément, 2005.

${ }^{80}$ Como lo señalara en su momento BARTH, 1969, las fronteras étnicas no aíslan geográfica y socialmente a los grupos que delimitan sino que persisten a pesar del flujo de personas y de rasgos culturales que las atraviesan, porque implican procesos sociales de exclusión y de incorporación mediante los cuales las categorías étnicas discretas se mantienen aunque cambien la participación y la pertenencia de los individuos que las componen. La etnicidad sería así un concepto dinámico no anclado en un conjunto inalterable de rasgos culturales sino en la permanente reelaboración de una noción del "nosotros" versus "los Otros" que recrea la percepción de un límite social.

${ }^{81}$ De La Cruz, 1969c, p. 486.

${ }^{82}$ MaAlouf, 1998, p. 33. La traducción es mía. 
La guerra puede ser desencadenada por una acusación de brujería, por el deseo de apropiarse del ganado y las mujeres de un contrincante, por los rumores que destilan ingenuos mocetones o pérfidos capitanes de amigos, por las manipulaciones de algún jefe de frontera español o, en el caso del secular enfrentamiento contra los cristianos, por la voluntad de defender el territorio contra una agresión exterior. $\mathrm{La}$ guerra estructura las sociedades indígenas en la medida en que es la vía de acceso de los hombres valerosos hacia la jefatura. El título de cacique o güilmen, explica De la Cruz, recae en los más ancianos o los más ricos, "que se granjean por sus hechos": en la batalla los hombres de dos grupos rivales intercambian violentamente mujeres, niños, ganados y bienes materiales que representan a la vez su fortuna y su honor. El prestigio y la riqueza son esenciales para ascender en la jerarquía política. La guerra hace al varón y es para él la ocasión de lucir su coraje personal, ya sea venciendo al adversario en épico combate, ya afrontando la muerte con bravura, "pues no es menos honroso en un Peguenche morir en manos de sus enemigos que ganar una victoria" $"$. Cada herida recibida en pelea se exhibe como un galardón y la muerte es aceptada con la confianza de que la honra así obtenida recaerá sobre todo el linaje, en cuyos miembros quedará el deber de vengarla. Si no se muestra valiente como su padre, el hijo de un cacique "nada es, y se mira como un mocetón despreciable" ${ }^{84}$. Lo que está en juego es el honor viril o el escarnio: "Hemos tomado las armas contra los pehuenches de Balbarco" -había intentado justificarse el joven cacique malargüino Millanguir- "por instancias de los mocetones y familias que los tenían por cobardes" si no vengaban el asesinato de su tío, gobernador de los pehuenches de Malargüe ${ }^{85}$. Los tenían por cobardes: afrenta suprema que legitima la más temeraria imprudencia, porque en un mozo el actuar impulsivamente se excusa aunque resulten nefastas las consecuencias del gesto, mientras que la cobardía es un baldón imborrable para él y todo su grupo familiar.

Guerra omnipresente pero no constante, ya que las actividades bélicas se suspenden cuando la nieve cierra los caminos en la cordillera o los ríos crecidos impiden el paso de los jinetes. Conflicto que pese a su ocasional virulencia no impide ni la circulación de correos ni el comercio y que puede resolverse, según las reglas ancestrales del ad mapu (derecho consuetudinario indígena) en encuentros protocolares donde cada parte es representada por un garante que tras enunciar los agravios recibidos negocia las compensaciones apropiadas, luego de lo cual se devuelven recíprocamente los cautivos y se hacen las paces con un gran festín redistributivo que restablece -por un tiempo al menos- la quebrada armonía.

"La nación más belicosa y brava entre los indios de todo el continente, es la de estos peguenches, según todos confiesan [...] sin embargo de ser la menor en número, y de que todos la temen" ${ }^{\text {"86: }}$ la guerra es constitutiva de la identidad pehuenche. El mismo ideal guerrero está presente en todos los pueblos de habla mapudugun que viven al oeste y al este de los Andes, al punto que Guillaume Boccara la considera

\footnotetext{
${ }^{83}$ De La Cruz, 1969a, p. 66.

${ }^{84}$ Ibidem, p. 449.

${ }^{85}$ Acta del parlamento de San Carlos. San Carlos, 12-VIII-1797. AHM, 30/33.

${ }^{86}$ De La Cruz, 1969c, p. 463.
} 
1a "institución central en la configuración étnica y la construcción identitaria" lo que la cultura compartida homogeneíza, lo que el parentesco tiende a acercar, la guerra lo separa, movilizando rencores hacia afuera y solidaridades hacia adentro: trazando límites. "La guerra representa el espacio en el cual se actualiza la figura del Otro y se constituye el Sí mismo. El otro necesario a la reproducción de la diferencia y de la sociedad" 88 .

Las fronteras étnicas, sin embargo, no nacen de una voluntad de cortar los contactos y cristalizar las diferencias con ese Otro en términos raciales o culturales sino, por el contrario, del ideal de asimilarlo en lo que Boccara denomina un "dispositivo de captación de la diferencia, de construcción del Sí mismo en un movimiento de apertura caníbal al Otro"89. La apropiación de la mujer y de los bienes del enemigo muerto, la adopción de los cautivos, la oportunidad brindada a los antiguos contrincantes acogidos como refugiados de pelear juntos, de "llevar la voz" en los malones y brindar consejo a los caciques principales demuestran un deseo intenso de absorber las cualidades del Otro, sacándoles el máximo provecho. En última instancia, la supervivencia de cada comunidad depende de su capacidad de dejar ir a los suyos y de adoptar a los ajenos, trocando al propio por el Otro ${ }^{90}$.

Más estables que las identidades individuales, los límites étnicos no son sin embargo permanentes: la mecánica guerrera imprime un movimiento constante al juego de oposiciones y alianzas en el que se ven envueltos los pueblos vecinos y a menudo emparentados. Pese a que los pehuenches de Balbarco eran los más enconados enemigos de huilliches, llanistas y ranqueles, cuando en 1796 se vieron acosados por sus parientes de Malargüe estuvieron a punto de unirse a aquellos. Si no se les brindaba protección militar para defenderse de los malargüinos -advertían al año siguiente"se retiraran á los Guilliches solicitando su alianza para vengar sus agravios" se trataba de vanas amenazas: poco después llegaría a Mendoza la noticia de que los pehuenches de Balbarco habían acudido a Naupayán, cacique principal de los ranqueles, para concertar un ataque conjunto contra los malargüinos, a lo que se negó el ranquel "por estar su sangre eslabonada con los de Malalgue" 92 . Parientes que se convierten en adversarios, enemigos atávicos que se niegan a pelear invocando los lazos del parentesco: los grupos étnicos, en permanente tensión entre la fuerza centrífuga de la guerra y la centrípeta de la sangre, reorientan sus impulsos agresivos y reformulan periódicamente sus alianzas.

Frente al flujo continuo de la historia, en el que nada es definitivo, la política española intentó fomentar las diferencias y congelar las adscripciones étnicas, jugando así un papel de primer orden en la siempre renovada dinámica guerrera y, por ende,

${ }^{87}$ Boccara, 1998, p. 86.

${ }_{88}^{8}$ Ibídem, 104. La traducción es mía.

${ }^{89}$ Ibidem, p. 101.

${ }^{90}$ BROOKs, 2002, p. 5.

${ }_{91}$ Oficio del virrey al gobernador Sobremonte. Buenos Aires, III-1796. AHM, 52/8; Oficio de Pedro Nolasco del Río al gobernador Luis de Alava. Los Ángeles, 8-V-1797. AGN, IX, 34-1-7.

${ }_{92}$ Carta de comandante José F. de Amigorena al gobernador Sobremonte. Mendoza, 21-XI-1797. AHM, 30/36. 
en los procesos de definición identitaria. Desde generaciones atrás, como vimos, los pehuenches se asumen como amigos privilegiados de los españoles y esa alianza político-militar será uno de los más poderosos detonantes de sus sangrientos conflictos internos y externos ${ }^{93}$. Hábilmente instrumentados por sus aliados cristianos, que a través de ellos incentivaban las divisiones y rencillas intertribales, los pehuenches se irían constituyendo - para sí mismos y para los demás- en un grupo cuya particularidad principal era justamente la lealtad a la causa española ${ }^{94}$. Habiendo comprendido que "introducida entre [los indios] la discordia y venganza no sosegarán hasta verse exterminados", don José Francisco de Amigorena, quien durante veinte años condujo la política fronteriza de Cuyo, admitió que sus esfuerzos por "introducirles esta discordia han correspondido según lo tenía meditado", lo que hacía necesario sostener militarmente a "estos aliados a quienes en todo caso será muy fácil el imponerles la ley". Tras la muerte de Llanquitur y sus principales lugartenientes, reconocería que los pehuenches "cada día se muestran más leales, y más enemigos de las demás Naciones, aún sin embargo el parentesco con que se hallan ligados los unos con los otros"

Cortejados por los españoles, quienes les brindan agasajos y asistencia militar al tiempo que reconocen a sus cabezas principales como caciques gobernadores y los distinguen con insignias prestigiosas (bastones de mando y uniformes militares), los pehuenches representan un caso notorio de etnificación - por el cual los hispanocriollos procuraron homogeneizar bajo una misma identidad a grupos que no constituían previamente una unidad política y mantenían serias desavenencias entre sí-, proceso al que vino a agregarse un fenómeno de etnización, en la medida en que la opción política -y por lo tanto contingente y sujeta a variaciones- de la alianza con los españoles fue convertida en atributo de etnicidad que diferenciaba a los pehuenches de sus vecinos huilliches y ranqueles, caracterizados en cambio por su implacable "rencor a los españoles", su condición de rebeldes o, como entonces se decía, de "alzados"96. El pehuenche que rompiera con esa alianza "se iba a los huilliches/ranqueles" física y metafóricamente ${ }^{97}$. Al desolidarizarse de sus parientes que se mantenían fieles a los

${ }_{93}$ En Chile, los pehuenches habían sido signatarios del tratado de Quillín (1641), primero de la larga serie de acuerdos diplomáticos que jalonarían la historia de las relaciones hispanoindígenas hasta 1803. En Quillín se habían comprometido a tratar como enemigos a los enemigos de los españoles. Desde 1647 se los encuentra peleando junto a éstos contra grupos huilliches (y recibiendo como contrapartida apoyo de destacamentos armados en sus conflictos con otros grupos), alianza militar que se activó con frecuencia a lo largo del siglo XVIII (véanse Villalobos, 1989 y ZaVala, 2000). Las autoridades chilenas se habían propuesto "afianzar la parcialidad de los indios pehuenches al partido de los españoles, para sujeción de las demás naciones indias", lo que justificaba que se les prestara asistencia militar (VILlalobos, 1989, p. 124). También en la frontera cuyana se les brindaba un trato especial al punto que, para españoles e indios por igual, las nociones de "indio pehuenche" e "indio amigo de españoles" terminaron convirtiéndose virtualmente en sinónimos. Véase también CASANOVA, 1996.

${ }^{94}$ Sobre la política española hacia los pehuenches de Malargüe véase RoulEt, 1999-2001 y 2002.

${ }^{95}$ Carta de Amigorena al gobernador Sobremonte. Mendoza, 15-VI-1790. AHM, 55/24; Carta de Amigorena al gobernador Sobremonte. Mendoza, 5-X-1791. AHM 55/28.

${ }^{96}$ Boccara, 2002 , p. 65 , señala estos fenómenos simultáneos de etnización y etnificación entre los pehuenches.

${ }_{97}$ De la Cruz asienta el testimonio del veterano soldado chileno Pedro Baeza, quien identifica a 
cristianos, los pehuenches de Ranquil habían roto simultáneamente con unos y otros. Luego de "abandonar a su nación" para refugiarse en las pampas, los emigrantes pudieron conducir libremente malones contra la frontera ${ }^{98}$. Cuando Puelmanc recuperó su identidad pehuenche, depuso las armas y retomó su condición de fiel aliado de los cristianos. Observamos así que, como bien lo señala Boccara, "la 'pehuencheidad' se definía fundamentalmente en función del contexto político, militar y económico [...]. Los pehuenches como grupo político y no como etnia, eran aliados de los españoles" pero esa condición de aliados se fue convirtiendo en atributo étnico ${ }^{99}$. A la inversa, quienes los combatían, fuera cual fuese su origen étnico, pasaban a ser rotulados como "huilliches", "ranqueles" y -un término que no aparece en el vocabulario de Luis de la Cruz pero que es frecuente en la documentación del siglo anterior- "aucas", o sea, "alzados".

\section{A MODO DE CONCLUSIÓN}

Las minuciosas observaciones de Luis de la Cruz nos abren una ventana para atisbar la complejidad y el dinamismo de los procesos de adscripción étnica, etnogénesis y etnización que estaban en marcha entre las sociedades nativas de Norpatagonia y las pampas en los albores del siglo XIX. La documentación de épocas anteriores sugiere que estos fenómenos de contacto, relaciones comerciales, mestizaje, guerra $\mathrm{y}$ asimilación venían de muy lejos ${ }^{100}$. Es evidente que los cambios introducidos por la conquista y colonización españolas y la manipulación consciente de las alianzas y conflictos intertribales potenciaron e imprimieron un ritmo acelerado a estos procesos.

A través de los numerosos discursos indígenas que salpican los escritos de Luis de la Cruz percibimos por un lado identidades étnicas colectivas, territorialmente circunscritas y relativamente estables -aunque ávidas de incorporar bienes e individuos exógenos mediante la guerra, el comercio y la asimilación por el parentesco, así como sujetas a variaciones demográficas y a la consiguiente expansión o retracción del espacio controlado por cada grupo- y, por otro lado, identidades individuales movedizas, construidas como un entramado de pertenencias diversas que se expresan

Llanquitur, Puelmanc, Quillan y Carripilum (antes de su emigración a las pampas) como huilliches. De LA Cruz, 1969c, p. 458. Esta era la designación que se solía aplicar en las fronteras mendocina y chilena a los indios del sur de Neuquén y de Mamilmapu, hostiles a la política española.

${ }^{98}$ De La Cruz, 1969a, p. 302.

${ }^{99}$ Boccara, 2002, p. 65.

${ }^{100}$ Por otra parte, las evidencias arqueológicas del inicio de la colonización humana de esos territorios hace más de diez mil años revelan ya entonces la presencia "desde el extremo meridional patagónico hasta la pampa bonaerense y sumando el centro de Chile (Tagua-Tagua 2)" de "una tecnología compartida por diversas poblaciones tempranas, muy móviles, en las que la circulación de información cumplía un papel importante en la subsistencia y la tecnología". Aschero, 2000, p. 34. Indicios más recientes en la pampa seca, datados hacia el 1200 d.C. (presencia de fragmentos de alfarería chilena de tipo Valdivia pintada, de obsidiana de origen cordillerano y de puntas de proyectil similares a las que se fabricaban en el norte de la Patagonia) "sugieren que los cazadores del oeste pampeano también formaban parte de redes de intercambio muy amplias y complejas que no sólo involucraban a indígenas vecinos, sino también a grupos extrarregionales". Politis, 2000, p. 95. 
de manera sucesiva y que tienen como correlato implícito una determinada actitud hacia el poder colonial. En cada fase de la existencia de un individuo una sola identificación prevalece, pero las anteriores han dejado su huella y pueden emerger a la superficie en cualquier momento. Así como el terruño natal y la familia de origen siguen siendo referencias primordiales, los lazos de afecto creados por el matrimonio, la adopción y los parentescos rituales generan vínculos intensos y duraderos que facilitan la genuina integración de emigrados y cautivos a los grupos que los acogen temporaria o definitivamente.

El testimonio del comisionado chileno nos muestra que, en las postrimerías del período colonial, el mundo indígena cordillerano, norpatagónico y pampeano ya está profundamente permeado por elementos esenciales de la cultura que hoy designamos como mapuche (en particular lengua y elaboración de textiles, ya que no aparecen en sus textos evidencias de platería ni de agricultura). Nos revela también mediante qué mecanismos -comercio, parentesco, migraciones individuales o grupales, adopción de cautivos de guerra y refugiados- ésta se ha ido extendiendo hacia el este, mezclándose con las de los grupos preexistentes en un proceso que no tiene nada de lineal porque los movimientos poblacionales y los juegos de alianzas son multidireccionales (indios de Mamilmapu que buscan en la cordillera refugio contra sus enemigos, magallánicos que acosan a huilliches, ranqueles que en su vejez regresan a la cordillera natal, llanistas que se aquerencian en los valles andinos...).

Del Pacífico al Atlántico, el mundo indígena que observa Luis de la Cruz está marcado por la movilidad geográfica y social, los intercambios, las mezclas, los conflictos y las negociaciones. Es vano buscar conglomerados étnicos compactos y cerrados al contacto con el exterior e ilusorio pretender habérselas con indios "puros" de una u otra nación. "La gente se encontraba y se mezclaba, se volvía bilingüe o multilingüe y circulaba hacia adentro y hacia afuera de sus grupos étnicos" ${ }^{101}$. El ser pehuenche, huilliche, llanista o ranquel no era una fatalidad genética sino una opción política que podía variar en el tiempo. La lectura de los textos del comisionado chileno nos recuerda que nada hay más escurridizo que un rótulo étnico ni más ajeno al modo de ser de estas sociedades que la obsesión occidental por la pureza de sangre. Lo genuinamente indígena es la apertura, la permeabilidad, la capacidad de asimilación de las diferencias:

[...] la máquina social indígena no sólo permite sino que necesita la mezcla, vale decir el mestizaje; se nutre del Otro [...] para elaborar su Ser; es decir, lo mestizo en este caso es lo indígena ${ }^{102}$.

${ }^{101}$ WeBER, 2005, p. 16.

102 Boccara, 2002, p. 28, negritas en el original. 


\section{REFERENCIAS BIBLIOGRÁFICAS}

Aschero, Carlos

2000 “El poblamiento del territorio”. En TARraGo (dir.), pp. 19-59.

Axtell, James

1992 Beyond 1492. Encounters in Colonial North America. New York Oxford. Oxford University Press.

BARTH, Frederick

1969 "Introduction". En BARTH, F. (ed.), Ethnic Groups and Boundaries. The Social Organization of Culture Difference. Bergen - London. Universitetsforlaget - George Allen and Unwin, pp. 9-38.

BECHIS, Martha

2003 "Pampas, serranos, puelches y aucas. A propósito del tratado de paz entre la gobernación de Buenos Aires y el cacique tehuelche-serrano Cangapol (1740-1742)". En GonzÁlez Coll, María Mercedes - FachinetTi, Graciela (comps.). En tierras australes. Imágenes, problemáticas y discursos. Bahía Blanca. Universidad Nacional del Sur, pp. 31-64.

2004 "A propósito de un documento puntano de 1710 en el que los vaqueros son unos caballeros asustados, los aucas respetan a las autoridades y los pampas-serranos son unos bárbaros asesinos". En BECHIS, Martha (comp.). Terceras Jornadas de Arqueología Histórica y de Contacto [...]. Cuartas Jornadas de Arqueología y Etnohistoria del Centro Oeste del país. Vol. IV. Río Cuarto. Universidad Nacional de Río Cuarto, pp. 13-34.

BocCARA, Guillaume

1998 Guerre et ethnogenèse mapuche dans le Chili colonial. L'invention de soi. Paris. L'Harmattan.

2002 "Colonización, resistencia y etnogénesis en las fronteras americanas". En Boccara (ed.), pp. 47-82.

BoccArA, Guillaume (ed.)

2002 Colonización, resistencia y mestizaje en las Américas, siglos XVI-XX. Quito. Abya Yala - Instituto Francés de Estudios Andinos.

Brooks, James F.

2002 Captives \& Cousins. Slavery, kinship and community in the Southwest borderlands. Chapel Hill and London. University of North Carolina Press.

Carretero, Andrés

1969 "El viaje de Luis de la Cruz en 1806". En De Angelis, pp. 9-34. 
Casanova, Holdenis

1996 "La alianza hispano-pehuenches y sus repercusiones en el macroespacio fronterizo sur andino (1750-1800)". En Pinto Rodríguez, Jorge (ed.). Araucania y Pampas. Un mundo fronterizo en América del Sur. Temuco. Ed. Universidad de la Frontera, pp. 72-92.

Cerro y Zamudio, José Santiago de

1972 Diario que da don José Santiago de Cerro y Zamudio [...] formado en el viaje para descubrimiento del camino sin cordillera, desde aquel reino [de Chile] a la ciudad de Buenos Aires [1803]. En De Angelis, Pedro. Colección de Obras y Documentos relativos a la Historia de las Provincias del Río de la Plata. Vol. VIIIa. Buenos Aires. Plus Ultra, pp. 40-46.

Clément, Vincent

2005 "Peuple de la forêt, peuple de la frontière. Identité et territoire des Indiens Pehuenches dans l'ancienne marche araucane (Chili, XVIeXXIe siècle)". Mélanges de la Casa de Velázquez. Madrid. $\mathrm{n}^{\mathrm{0}}$ 35:2, pp. 125-145. Versión digital disponible en http://mcv.revues.org/2098.

Crivelli Montero, Eduardo

1994 “Araucanos en las pampas". Todo es Historia. Buenos Aires. nº 323, pp. 8-32.

De Ángelis, Pedro

1969 Colección de Obras y Documentos relativos a la Historia de las Provincias del Río de la Plata. Vol. II. Buenos Aires. Plus Ultra.

De La Cruz, Luis

1969a "Viaje a su costa del alcalde provincial del muy ilustre cabildo de la Concepción de Chile don Luis de la Cruz desde el fuerte de Ballenar, frontera de dicha Concepción, por tierras desconocidas, y habitadas de indios bárbaros, hasta la ciudad de Buenos Aires " [1806]. En DE ANGELIS, pp. 45-385.

1969b "Descripción de la naturaleza de los terrenos que se comprenden en los Andes poseídos por los Peguenches y los demás espacios hasta el río de Chadileubú reconocidos por don Luis de la Cruz, Alcalde Mayor Provincial del Ilustre Cabildo de la Concepción de Chile" [1806]. En De ANGelis, pp. 401-436.

1969c "Tratado importante para el perfecto conocimiento de los indios peguenches, según el orden de su vida" [1806]. En De Angelis, pp. 437-491.

EsCoLAR, Diego

2000 "Identidades emergentes en la frontera argentino-chilena. Subjetividad y crisis de soberanía en la población andina de la provincia de San Juan". En Grimson, Alejandro (comp.). Fronteras, naciones e identidades. La periferia como centro. Buenos Aires. Ed. La Crujía. pp. 256-277.

ERIZE, Esteban

1989 Mapuche. $3^{\text {a }}$. ed. Buenos Aires. Yepun. 
FERNÁNDEZ, Jorge

1982 Viaje desde Linares a las nacientes de los ríos Barrancas, Neuquén y Varvarco, por tierras de indios, efectuado en 1804 por el capitán José Barros. Neuquén. Archivo Histórico Provincial.

LIENHARD, Martín

1998 "El cautiverio colonial del discurso indígena". En PinTo RodRíguez, Jorge. Del discurso colonial al proindigenismo. Ensayos de historia latinoamericana. Temuco. Ediciones Universidad de la Frontera, pp. 9-28.

LeÓN Solís, Leonardo

1998 "Guerras pehuenche-huilliche en Araucanía y las pampas, 1760-1765". Historia. Santiago. $\mathrm{n}^{\circ}$ 31, pp. 113-145.

MaAlouf, Amin

1998 Les identités meurtrières. Paris. Grasset.

NAcuzZI, Lidia

1998 Identidades impuestas. Tehuelches, aucas y pampas en el norte de la Patagonia. Buenos Aires. Sociedad Argentina de Antropología.

2002 "Los grupos, los nombres, los territorios y los blancos: historia de algunos nombres étnicos”. En Boccara (ed.), pp. 259-290.

ORTELLI, Sara

1996 "La "araucanización" en las pampas: ¡realidad histórica o construcción de los etnólogos?”. Anuario del IEHS. Tandil. nº 11, pp. 203-225.

Palermo, Miguel Angel

1991 "La compleja integración hispano-indígena del sur argentino y chileno durante el período colonial”. América Indígena. México. $\mathrm{n}^{\circ} 51,1, \mathrm{pp}$. 153-192.

Politis, Gustavo

2000 "Los cazadores de la llanura". En TARRAGO (dir.), pp. 61-103.

Poutignat, Philippe y Streiff-Fenart, Jocelyne

1995 Théories de l'ethnicité. Paris. PUF.

Rosas, Juan Manuel de

1995 Gramática y diccionario de la lengua pampa (pampa-ranquelaraucano). Buenos Aires. Theoria.

ROULET, Florencia

1999-2001 "De cautivos a aliados: los "indios fronterizos" de Mendoza (17801806)". Xama. Mendoza. no 12-14, pp. 199-239.

2002 "Guerra y diplomacia en la frontera de Mendoza: la política indígena del comandante José Francisco de Amigorena (1779-1799)". En NACUZzI, Lidia (comp.). Funcionarios, diplomáticos, guerreros. Miradas 
hacia el otro en las fronteras de Pampa y Patagonia (siglos XVIII y $X I X)$. Buenos Aires. Sociedad Argentina de Antropología, pp. 65-117.

2003 "Ojos de exiliado. Notas al margen de una lectura de las Memorias de Manuel Baigorria". Investigaciones y ensayos. Buenos Aires. $n^{\circ} 53$, pp. 265-300.

2006 "Fronteras de papel. El periplo semántico de una palabra en la documentación relativa a la frontera sur rioplatense en los siglos XVIII y XIX". Revista TEFROS. $\mathrm{n}^{\mathrm{o}}$ 4: 2. Texto digital disponible en: www. tefros.com.ar/revista/v4n2p06/paquetes/roulet.pdf.

2008 "Embajadoras y hechiceras indígenas. El poder de las mujeres en la frontera sur". Todo es Historia. Buenos Aires. n 489, pp. 6-24.

2009 "Mujeres, rehenes y secretarios: mediadores indígenas en la frontera sur del Río de la Plata durante el período hispano". Colonial Latin American Review. New York. vol. 18, n 3, pp. 303-337.

TARRAGO, Miriam (dir.)

2000 Nueva Historia Argentina. Tomo I: Los pueblos originarios y la conquista. Buenos Aires. Sudamericana.

Villalobos, Sergio

1989 Los pehuenches en la vida fronteriza. Santiago. Universidad Católica de Chile.

WeBER, David

2005 Bárbaros. Spaniards and their Savages in the Age of Enlightenment. New Haven \& London. Yale University Press.

Zavala, José Manuel

2000 Les Indiens Mapuche du Chili. Dynamiques inter-ethniques et stratégies de résistance, XVIIIe. siècle. Paris. L'Harmattan. 